\title{
əIntraseasonal Sea Level Variability in the Persian Gulf
}

\author{
CHristopher G. PIECUCH, ${ }^{\mathrm{a}}$ ICHIRO FuKUMORI, ${ }^{\mathrm{b}}$ AND RUi M. PONTE ${ }^{\mathrm{c}}$ \\ ${ }^{\mathrm{a}}$ Woods Hole Oceanographic Institution, Woods Hole, Massachusetts \\ ${ }^{\mathrm{b}}$ NASA Jet Propulsion Laboratory, Pasadena, California \\ ${ }^{\mathrm{c}}$ Atmospheric and Environmental Research, Inc., Lexington, Massachusetts
}

(Manuscript received 2 December 2020, in final form 8 March 2021)

\begin{abstract}
Satellite observations are used to establish the dominant magnitudes, scales, and mechanisms of intraseasonal variability in ocean dynamic sea level $(\zeta)$ in the Persian Gulf over 2002-15. Empirical orthogonal function (EOF) analysis applied to altimetry data reveals a basinwide, single-signed intraseasonal fluctuation that contributes importantly to $\zeta$ variance in the Persian Gulf at monthly to decadal time scales. An EOF analysis of Gravity Recovery and Climate Experiment (GRACE) observations over the same period returns a similar large-scale mode of intraseasonal variability, suggesting that the basinwide intraseasonal $\zeta$ variation has a predominantly barotropic nature. A linear barotropic theory is developed to interpret the data. The theory represents Persian Gulf average $\zeta(\bar{\zeta})$ in terms of local freshwater flux, barometric pressure, and wind stress forcing, as well as $\zeta$ at the boundary in the Gulf of Oman. The theory is tested using a multiple linear regression with these freshwater flux, barometric pressure, wind stress, and boundary $\zeta$ quantities as input and $\bar{\zeta}$ as output. The regression explains $70 \% \pm 9 \%$ (95\% confidence interval) of the intraseasonal $\bar{\zeta}$ variance. Numerical values of regression coefficients computed empirically from the data are consistent with theoretical expectations from first principles. Results point to a substantial nonisostatic response to surface loading. The Gulf of Oman $\zeta$ boundary condition shows lagged correlation with $\zeta$ upstream along the Indian subcontinent, Maritime Continent, and equatorial Indian Ocean, suggesting a large-scale Indian Ocean influence on intraseasonal $\bar{\zeta}$ variation mediated by coastal and equatorial waves and hinting at potential predictability. This study highlights the value of GRACE for understanding sea level in an understudied marginal sea.
\end{abstract}

KEYWORDS: Coastlines; Sea level; Satellite observations; Intraseasonal variability

\section{Introduction}

The Persian Gulf ${ }^{1}$ is a semienclosed marginal sea of the Indian Ocean (Fig. 1). It connects to the Arabian Sea to the southeast through the Strait of Hormuz and the Gulf of Oman. The Persian Gulf is shallow and broad, with an average depth of $\sim 30 \mathrm{~m}$ and a surface area of $\sim 2.2 \times 10^{5} \mathrm{~km}^{2}$. It is subject to an arid, subtropical climate and is bounded to the southwest by the Arabian Desert and by the Zagros Mountains to the northeast.

Past studies have established the basic physical oceanography of the Persian Gulf using data and models (Chao et al. 1992; Emery 1956; Johns et al. 1999, 2003; Kämpf and Sadrinasab 2006; Reynolds 1993; Thoppil and Hogan 2010; Swift and Bower 2003; Yao and Johns 2010). We outline some of the salient features for context. The region is forced year-round by north-northwesterly surface winds ("shamal," speeds $3-6 \mathrm{~m} \mathrm{~s}^{-1}$ ). Evaporation

\footnotetext{
${ }^{1}$ The name of this body of water is subject to dispute. It is also known as the Arabian Gulf or the Gulf. We use the name Persian Gulf following the conventions of the International Hydrographic Organization and the United Nations.
}

¿ Denotes content that is immediately available upon publication as open access.

Corresponding author: Christopher G. Piecuch, cpiecuch@whoi.edu $\left(\sim 2 \mathrm{~m} \mathrm{yr}^{-1}\right)$ far exceeds precipitation and runoff $\left(\sim 0.2 \mathrm{~m} \mathrm{yr}^{-1}\right)$, resulting in an inverse-estuarine circulation-fresher, warmer buoyant waters inflow near the surface through the Strait of Hormuz largely along the coast of Iran, whereas saltier, colder, denser waters outflow near the bottom mainly along the coast of the United Arab Emirates. The basin-scale circulation is demarcated by a thermal front across the Persian Gulf between Qatar and Iran. Northwest of the front, there is equatorward flow along Saudi Arabia driven by wind-forced downwelling at the coast and buoyant river discharge from the Tigris, Euphrates, and other rivers at the head of the Persian Gulf. To the southeast, there exists a large-scale counterclockwise circulation, maintained by exchanges through the Strait of Hormuz, and evaporation, cooling, and sinking of water masses in shallow regions along the southern Persian Gulf. Mesoscale eddies are common, especially during boreal summer, when they are shed from the Iranian coastal jet due to baroclinic instability. There is a seasonal cycle in the vertical stratification, such that top-to-bottom potential density contrasts are weaker in winter $\left(0-1 \mathrm{~kg} \mathrm{~m}^{-3}\right)$ and stronger in summer $\left(2-5 \mathrm{~kg} \mathrm{~m}^{-3}\right)$. For more details, interested readers are directed to the papers cited above.

The Persian Gulf is one of the World Ocean's busiest waterways due to its vast oil and gas stores, which are of long-standing geopolitical, economic, and military interest (al-Chalabi 2007; Barnes and Myers Jaffe 2006; Larson 2007). Bordering eight nations, the Persian Gulf is also home to large coastal populations and major coastal cities including Dubai and Abu Dhabi, United Arab Emirates, and Doha, Qatar, 


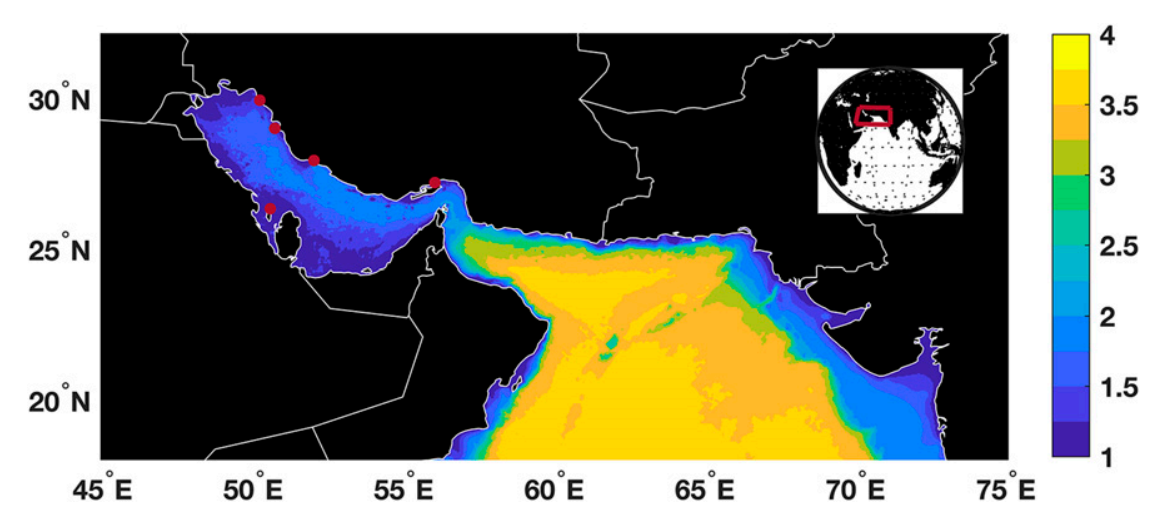

FIG. 1. Study area. White lines indicate national boundaries. Color shading identifies ocean depth. (Note the logarithmic scale bar and units of $\log _{10} \mathrm{~m}$.) Red dots denote locations of tide gauges (Table 2). The inset shows the study area in a global context.

which are exposed to risk of flooding and inundation related to sea level change (Al-Jeneid et al. 2008; Lafta et al. 2020). Kopp et al. $(2014,2017)$ project that mean sea level will rise by 44 $108 \mathrm{~cm}$ between 2000 and 2100 in Bahrain under the representative concentration pathway 8.5 forcing scenario ( $66 \%$ confidence). This would threaten $\sim 10 \%-15 \%\left(\sim 80-100 \mathrm{~km}^{2}\right)$ of Bahrain's surface area (Al-Jeneid et al. 2008). Such numbers emphasize the importance of understanding sea level changes in the Persian Gulf. However, projections of mean sea level rise on multidecadal and longer time scales (Kopp et al. 2014, 2017) alone are insufficient to anticipate future coastal flood risk. Also important are sea level fluctuations at decadal and shorter periods, which can superimpose on longer-term changes, temporarily ameliorating or exacerbating coastal risk (Burgos et al. 2018; Dangendorf et al. 2016; Long et al. 2020; Ray and Foster 2016; Sweet et al. 2017). This motivates a detailed investigation of mean sea level variation in the Persian Gulf on decadal and shorter time scales-what are the dominant magnitudes, scales, and mechanisms?

Past studies on Persian Gulf mean sea level largely focus on seasonal cycles and decadal trends (Al-Subhi 2010; Alothman et al. 2014; Ayhan 2020; Barzandeh et al. 2018; El-Gindy 1991; El-Gindy and Eid 1997; Hassanzadeh et al. 2007; Hosseinibalam et al. 2007; Sharaf El Din 1990; Siddig et al. 2019; Sultan et al. 1995a, 2000). Sultan et al. (1995a) consider monthly relative sea level during 1980-90 from two tide gauges on the Saudi Arabia coast. They find that $80 \%$ of the overall monthly data variance is explained by the seasonal cycle, which has an amplitude of $\sim 10 \mathrm{~cm}$ and peaks in boreal summer. These authors argue that $75 \%$ of the seasonal variance in sea level reflects an inverted-barometer response to a 10-mb-amplitude seasonal cycle $(1 \mathrm{mb}=1 \mathrm{hPa})$ in local surface air pressure, and that the remaining $25 \%$ of seasonal variance represents steric variability owing to density fluctuations. Other studies targeting different regions, tide gauges, and time periods confirm this basic result that invertedbarometer and steric effects make primary and secondary contributions, respectively, to the large-scale seasonal cycle in Persian Gulf sea level, but also suggest that local wind effects are important in some places (Al-Subhi 2010; Barzandeh et al. 2018; El-Gindy 1991; El-Gindy and Eid 1997; Hassanzadeh et al. 2007;
Hosseinibalam et al. 2007; Sharaf El Din 1990; Sultan et al. 2000). Alothman et al. (2014) interrogate monthly relative sea level over 1979-2007 based on 15 tide gauge records from Bahrain, Saudi Arabia, and Iran, along with measurements of vertical land motion from six global positioning system (GPS) stations in Bahrain, Saudi Arabia, and Kuwait. They determine that regional relative sea level rose by $2.2 \pm 0.5 \mathrm{~mm} \mathrm{yr}^{-1}$ over that time. These authors find that one-third of the increase $\left(0.7 \pm 0.6 \mathrm{~mm} \mathrm{yr}^{-1}\right)$ was due to crustal subsidence, possibly related to groundwater pumping and oil extraction (Amin and Bankher 1997), and the remaining twothirds $\left(1.5 \pm 0.8 \mathrm{~mm} \mathrm{yr}^{-1}\right)$ was due to geocentric sea level changes. Sultan et al. (2000) calculate a more muted relative sea level trend $\left(1.7 \mathrm{~mm} \mathrm{yr}^{-1}\right)$ based on nine tide gauge records from Saudi Arabia over 1980-94, while Siddig et al. (2019) estimate a larger geocentric sea level trend $\left(3.6 \pm 0.4 \mathrm{~mm} \mathrm{yr}^{-1}\right)$ from altimetry data averaged over the Persian Gulf during 1993-2018, consistent with reports of a global sea level acceleration in recent decades (Nerem et al. 2018; Dangendorf et al. 2019; Frederikse et al. 2020).

Omitted from past works on Persian Gulf mean sea level is exploration of nonseasonal sea level variation. This is an important omission, since nonseasonal variations in general, and in particular intraseasonal variations, contribute importantly to mean sea level variance over the Persian Gulf on monthly to decadal time scales. For example, consider the time series of monthly ocean dynamic sea level ${ }^{2}$ from satellite-altimetry data averaged over the Persian Gulf during 2002-15 shown in Fig. 2. Filters are applied to the data to emphasize variability on different time scales, and global-mean sea level and the invertedbarometer effect are removed. Nonseasonal fluctuations explain $52 \%$ of the monthly data variance, and intraseasonal fluctuations (with 2-6-month periods) alone account for $46 \%$ of the overall data variance. The altimetric time series of intraseasonal sea level averaged over the Persian Gulf also explains $51 \%$ of the intraseasonal variance in relative sea level averaged across five tide gauges from Iran and Bahrain during

\footnotetext{
${ }^{2}$ Ocean dynamic sea level is the local height of the sea surface above the geoid adjusted for the inverted-barometer effect (Gregory et al. 2019).
} 


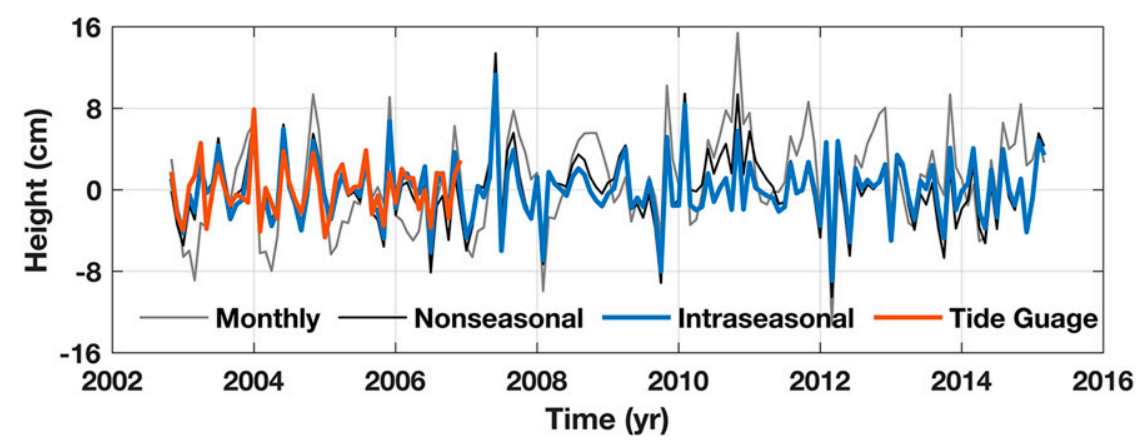

FIG. 2. Monthly ocean dynamic sea level in the Persian Gulf between November 2002 and March 2015 from satellite altimetry (gray, black, blue) and tide gauges (orange). The satellitealtimetry data are spatially averaged over the Persian Gulf whereas the tide gauge data represent a composite average over five sites (Fig. 1). The raw monthly altimetry data are shown in gray, whereas the black and blue indicate the altimetry data with filtering applied to isolate nonseasonal and intraseasonal time scales, respectively. The tide gauge data (orange) have been filtered to isolate intraseasonal periods and adjusted for the inverted-barometer effect. The standard deviations of the gray, black, blue, and orange time series are 4.7, 3.5, 3.0, and $2.5 \mathrm{~cm}$, respectively.

the overlapping period 2002-06 (Fig. 2). This exploratory analysis suggests that large-scale intraseasonal fluctuations make important contributions to ocean dynamic sea level variance across the Persian Gulf during the altimeter era, motivating a more in-depth investigation.

Here we investigate the magnitudes, scales, and mechanisms of intraseasonal sea level variability in the Persian Gulf through an analysis of satellite observations, tide gauges, reanalysis products, and gridded surface flux estimates. The remainder of the paper is structured as follows: in section 2, we describe the data. In section 3, we establish the horizontal scales and vertical structure of the dominant intraseasonal sea level variation in the Persian Gulf. In section 4, we use dynamical theory, linear regression, and correlation analysis to identify the main local and nonlocal forcing mechanisms and ocean dynamics responsible for driving intraseasonal variations in Persian Gulf sea level and their relation to large-scale circulation and climate in the equatorial and north Indian Ocean. We conclude with a summary and discussion in section 5 .

\section{Materials and methods}

\section{a. Ocean dynamic sea level from satellite altimetry}

We use version 2.0 of the sea level essential climate variable product from the European Space Agency Climate Change
Initiative (Legeais et al. 2018; Quartly et al. 2017). Data were downloaded from the Centre for Environmental Data Analysis on 18 April 2020 (all data sources are indicated in Table 1). The multisatellite merged geocentric sea level anomalies are given on a $0.25^{\circ}$ global spatial grid and a monthly time increment during 1993-2015. These data extend and update the earlier version 1.1 product (Ablain et al. 2015). The dynamic atmospheric correction is applied, which involves removing the ocean's dynamic barotropic response to wind and pressure forcing at shorter periods $<20$ days and its isostatic response to pressure forcing at longer periods $>20$ days from the data (Carrère and Lyard 2003; Carrère et al. 2016). (The dynamic ocean response to these forcings at the periods of interest to this study are retained in the data.) For more details on the geophysical corrections, orbit solutions, altimeter standards, and error budgets, see Quartly et al. (2017) and Legeais et al. (2018). We remove the time series of global-mean geocentric sea level values from every grid cell, and the resulting sea level anomalies mainly reflect ocean dynamic sea level anomalies. [We do not adjust the altimetry, or any other dataset, for the spatially variable effects of gravitation, rotation, and deformation related to contemporary surface ice and water mass redistribution, since these effects are negligible in this area on these time scales (Adhikari et al. 2019)]. We use these data from May 2002 to September 2015, which corresponds roughly to the quasi-continuous Gravity Recovery and Climate

TABLE 1. Data sources. All websites are current as of this writing.

\begin{tabular}{|c|c|}
\hline Dataset & URL \\
\hline Altimetry & ftp://anon-ftp.ceda.ac.uk/neodc/esacci/sea_level/data/L4/MSLA/v2.0/ \\
\hline GRACE & https://podaac.jpl.nasa.gov/dataset/TELLUS_GRAC-GRFO_MASCON_CRI_GRID_RL06_V2 \\
\hline Tide gauges & https://www.psmsl.org/data/obtaining/complete.php \\
\hline ERA-Interim & http://cmip5.whoi.edu/?page_id=566 \\
\hline GPCP & https://psl.noaa.gov/data/gridded/data.gpcp.html \\
\hline OAFlux & ftp://ftp.whoi.edu/pub/science/oaflux/data_v3/monthly/evaporation/ \\
\hline JRA55-do & http://amaterasu.ees.hokudai.ac.jp/ tsujino/JRA55-do-suppl/runoff/ \\
\hline
\end{tabular}


TABLE 2. Description of tide gauge records. An asterisk indicates metric data without complete datum histories.

\begin{tabular}{|c|c|c|c|c|c|c|}
\hline Station name & Nation & PSMSL identifier & Lon $\left({ }^{\circ} \mathrm{E}\right)$ & Lat $\left({ }^{\circ} \mathrm{N}\right)$ & Span & Completeness \\
\hline Mina Sulman & Bahrain & 1494 & 50.6 & 26.2 & 1979-2006 & $66.1 \%$ \\
\hline Emam Hassan* & Iran & 1868 & 50.3 & 29.8 & 1995-2006 & $91.7 \%$ \\
\hline Bushehr* & Iran & 1939 & 50.8 & 28.9 & $2004-06$ & $100.0 \%$ \\
\hline Kangan* & Iran & 1869 & 52.1 & 27.8 & 1995-2006 & $98.6 \%$ \\
\hline Shahid Rajaee* & Iran & 1870 & 56.1 & 27.1 & 1995-2006 & $100.0 \%$ \\
\hline
\end{tabular}

Experiment (GRACE) record that is used for interpretation and described below. Following Gregory et al. (2019), we use $\zeta$ to denote ocean dynamic sea level.

This paper focuses on intraseasonal variability. To isolate intraseasonal behavior, we process the data as follows: We use least squares to estimate the seasonal cycle (annual and semiannual sinusoids) and linear trend in the data over the study period. We then remove these seasonal and trend contributions from the original data to create a time series of nonseasonal residuals. Next, we apply a Gaussian smoother with a 3-month half window to these nonseasonal residuals. Finally, we subtract this low-pass-filtered time series from the nonseasonal residuals to create a record of intraseasonal fluctuations, which is the object of our study. We delete the first and last 6 months of the intraseasonal time series to avoid edge effects. This filter passes $>90 \%$ of the power at periods $\$ 8$ months and stops $>70 \%$ of the power at periods $\gtrsim 15$ months. See Fig. 2 for an example of this filtering applied to altimetry averaged over the Persian Gulf.

\section{b. Manometric sea level from satellite gravimetry}

We consider data from GRACE and GRACE Follow-On (Landerer et al. 2020; Watkins et al. 2015; Wiese et al. 2016). Mass grids were downloaded from the National Aeronautics and Space Administration Jet Propulsion Laboratory on 15 April 2020 (data version JPL RL06M.MSCNv02). The data are processed using $3^{\circ}$ spherical-cap mass-concentration blocks for the gravity-field basis functions. For more details on the estimation process, spatial constraints, scale factors, and leakage errors, see Watkins et al. (2015). The data are defined on a $0.5^{\circ}$ global spatial grid, but the satellite measurements do not resolve processes with spatial scales $\$ 300 \mathrm{~km}$. We use the version of the data with the coastline resolution improvement filter applied (Wiese et al. 2016). The grids are defined at irregular, quasi-monthly increments, and have gaps. For example, battery management issues caused multimonth data gaps in the final years of GRACE, and there is a $\sim 1$-yr data gap between the end of GRACE coverage and the beginning of the GRACE Follow-On record. We linearly interpolate the available ocean mass grids onto regular monthly increments from May 2002 through September 2015. The data have units of equivalent water thickness. After correcting for global air pressure effects, these data reflect manometric sea level anomalies. ${ }^{3}$ To isolate dynamic manometric sea level anomalies

\footnotetext{
${ }^{3}$ Manometric sea level changes indicate sea level changes due to changes in the local mass of the ocean per unit area (Gregory et al. 2019).
}

associated with internal ocean mass redistribution, we subtract the time series of barystatic sea level ${ }^{4}$ from the data at every oceanic grid cell. Intraseasonal variations are isolated through filtering methods described earlier. Following Gregory et al. (2019), we use $R_{m}$ to indicate manometric sea level, with its dynamic nature understood.

\section{c. Relative sea level from tide gauges}

We also use monthly mean relative sea level ${ }^{5}$ from tide gauge records in the Persian Gulf that overlap with our study period (Table 2). Data were downloaded from the Permanent Service for Mean Sea Level (PSMSL) database on 1 July 2019 (PSMSL 2020; Holgate et al. 2013). The data from Mina Sulman in Manama, Bahrain, represent the only record from the Persian Gulf in the PSMSL database with a complete benchmark datum history (so-called revised local reference data). To consider large-scale regional behavior, we also study a careful selection of records without continuous datum histories (so-called metric data). Namely, we use the data from Emam Hassan, Bushehr, Kangan, and Shahid Rajaee in Iran. ${ }^{6}$ We consider the data over 2002-06, since earlier times predate our study, and later times feature no tide gauge data (Table 2). The data from Emam Hassan before November 2002 are omitted due to a data gap that coincided with an apparent datum shift (Alothman et al. 2014). We adjust each record for the inverted-barometer effect using reanalysis surface air pressure (see below). Next, we remove the seasonal cycle and linear trend from each adjusted time series. We then average together these nonseasonal time series to create a regional composite of adjusted relative sea level. Finally, we isolate intraseasonal variability by computing and then removing a low-pass-filtered version of the regional composite. The resulting time series is shown in Fig. 2. To the extent that global-mean sea level changes are unimportant, this composite

\footnotetext{
${ }^{4}$ Barystatic sea level changes refer to global-mean manometric sea level changes and correspond to net addition or subtraction of water mass to or from the global ocean (Gregory et al. 2019).

${ }^{5}$ Relative sea level is the height of the sea surface relative to the solid Earth (Gregory et al. 2019).

${ }^{6}$ Metric data from other Persian Gulf locations are also available in the PSMSL database. However, we determined that these records were unsuitable for our analysis. Five records from the United Arab Emirates, Qatar, and Iraq are short and predate our study period. A dozen records from Saudi Arabia were operated by the Saudi Arabian Oil Company and situated on oil platforms and are therefore potentially unstable.
} 
time series represents tide gauge-based intraseasonal regional $\zeta$ variability.

To establish regional context, we also consider all 53 monthly mean relative sea level records in the PSMSL revised local reference database in the equatorial and north Indian Ocean $\left(40^{\circ}\right.$ $\left.105^{\circ} \mathrm{E}, 12.5^{\circ} \mathrm{S}-32.5^{\circ} \mathrm{N}\right)$ with $\geq 84$ months of data during $2002-15$ ( $250 \%$ data completeness over the study period). These data are also adjusted for the inverted-barometer effect and filtered to isolate intraseasonal behavior as described above.

\section{d. Surface forcing}

We use gridded observations, atmospheric reanalyses, and flux estimates to interpret the data from altimetry, GRACE, and tide gauges. For all fields, we compute intraseasonal anomalies during 2002-15 from the available monthly values, as with the altimetry and GRACE.

We use monthly wind stress and barometric pressure from the European Centre for Medium-Range Weather Forecasts interim reanalysis (ERA-Interim; Dee et al. 2011). Fields were downloaded from the Woods Hole Oceanographic Institution (WHOI) Community Storage Server on 7 January 2019. Values are defined on a $0.75^{\circ}$ global spatial grid from January 1979 to October 2018.

We use monthly evaporation from version 3 of the Objectively Analyzed Air-Sea Fluxes project (OAFlux; Yu and Weller 2007). Fields were downloaded from WHOI servers on 13 November 2019. Values are defined on a $1^{\circ}$ global spatial grid from January 1958 to December 2018.

We use monthly precipitation from version 2.3 of the Global Precipitation Climatology Project (GPCP; Adler et al. 2003). Fields were downloaded from the National Oceanic and Atmospheric Administration Earth System Research Laboratory and Physical Sciences Laboratory on 16 April 2020. Values are defined on a $2.5^{\circ}$ global spatial grid from January 1979 to the present.

We use monthly river runoff from the Japanese 55-yr atmospheric reanalysis surface dataset for driving ocean-sea ice models (JRA55-do; Tsujino et al. 2018). Fields were downloaded from servers at the Hokkaido University Graduate School of Environmental Science on 21 August 2020. Values are defined on a $0.25^{\circ}$ global coastal grid from January 1958 to December 2017.

\section{Horizontal scales and vertical structure of $\zeta$ variability}

Past studies use satellite altimetry and tide gauges to study seasonal cycles and decadal trends in the Persian Gulf (Al-Subhi 2010; Alothman et al. 2014; Ayhan 2020; El-Gindy 1991; El-Gindy and Eid 1997; Hassanzadeh et al. 2007; Hosseinibalam et al. 2007; Sharaf El Din 1990; Siddig et al. 2019; Sultan et al. 1995a, 2000). Here we examine intraseasonal variability in the Persian Gulf using satellite data, including altimetry but also gravimetry, and tide gauges.

We motivated this study with an exploratory data analysis earlier in the introduction. We found that roughly half of the monthly $\zeta$ variance from altimetry averaged over the Persian Gulf during 2002-15 was concentrated at intraseasonal periods, and that the Persian Gulf-average altimetric time series
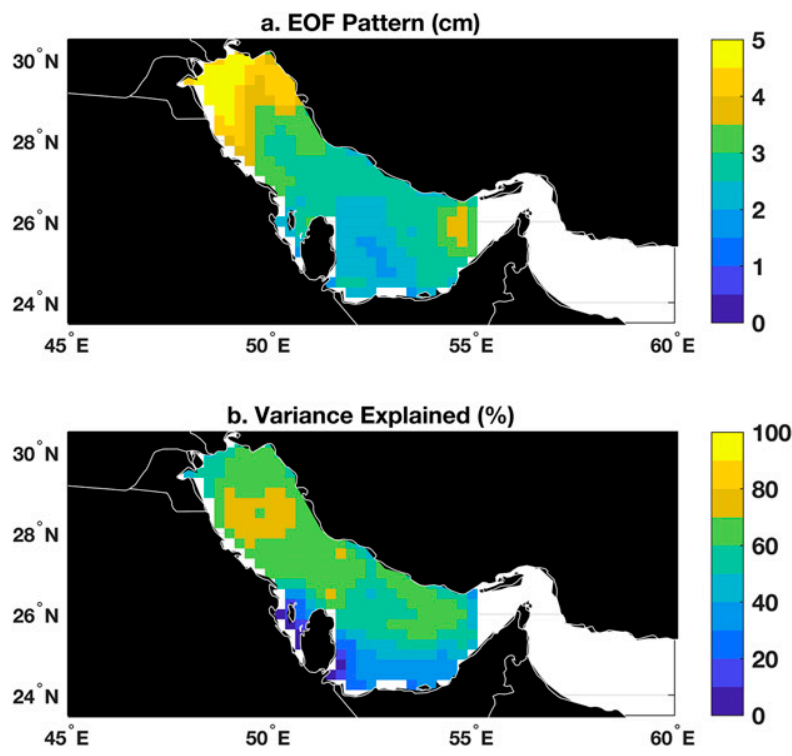

FIG. 3. (a) Spatial pattern (eigenvector) of the first $\zeta$ EOF mode across the Persian Gulf from intraseasonal altimetry data (units are $\mathrm{cm}$ ). (b) Local $\zeta$ variance explained by the first EOF mode (units are percent of total variance).

of intraseasonal $\zeta(\bar{\zeta})$ explained about half of the variance in a composite time series of intraseasonal $\zeta$ from coastal tide gauges (Fig. 2). These results show that intraseasonal fluctuations contribute importantly to large-scale $\zeta$ variability over the Persian Gulf at monthly to decadal periods, and that intraseasonal fluctuations measured locally at the coast largely reflect spatially coherent, basinwide behavior.

To explore intraseasonal $\zeta$ in more detail, we apply empirical orthogonal function (EOF) analysis to altimetry data over the Persian Gulf. We identify the spatial structures and temporal behaviors of the orthogonal modes of intraseasonal variability by solving for the eigenvalues and eigenvectors of the covariance matrix of the altimetry data over the Persian Gulf. The eigenvectors correspond to the spatial structures and the eigenvalues indicate the amounts of data variance explained by the various modes. The temporal behaviors of the modes are described by principal component time series, which are determined by projecting the respective eigenvectors onto the data (von Storch and Zwiers 1999).

The leading mode, which explains $52 \%$ of the intraseasonal data variance over the Persian Gulf, is summarized in Figs. 3 and 4 . It shows a single-signed spatial structure (Fig. 3a), indicating basinwide variation and wholesale raising and lowering of $\zeta$ over the Persian Gulf. This is consistent with our earlier finding that the $\bar{\zeta}$ time series from altimetry explains $51 \%$ of the variance in the regional composite from tide gauges at intraseasonal time scales (Fig. 2). Indeed, this mode's principal component time series (Fig. 4) is perfectly correlated with the $\bar{\zeta}$ time series from altimetry (correlation coefficient $>0.99$ ). The leading mode from a complex-valued (Hilbert) EOF analysis explains the same amount of data variance (not shown). This means that out-of-phase relationships between $\zeta$ in different parts of the Persian Gulf related to signal propagation are 


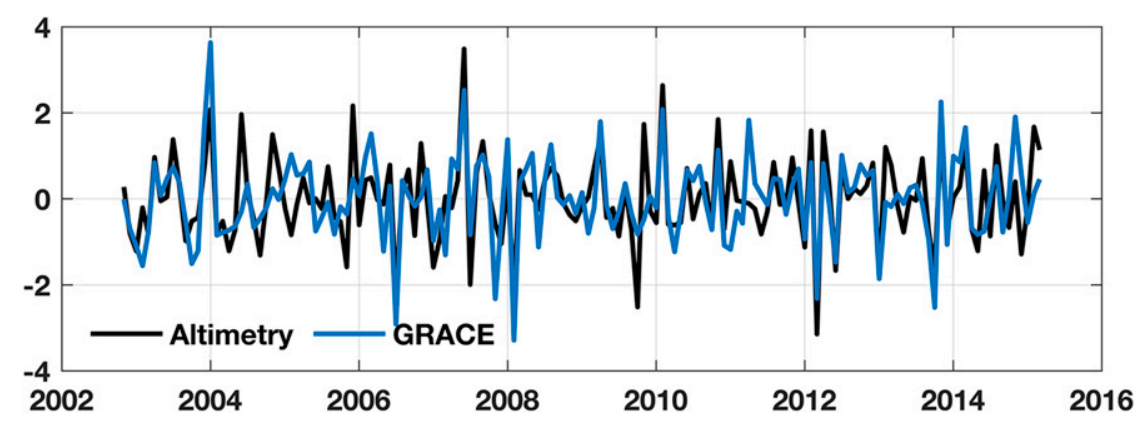

FIG. 4. Principal component time series of the first EOF modes from altimetry $\zeta$ (black) and GRACE $R_{m}$ (blue) over the Persian Gulf. Time series have been normalized to unit variance (physical units are shown for the eigenvectors in Figs. 3 and 5).

unimportant to this mode, and that this dominant $\zeta$ variation reflects an in-phase standing mode of oscillation across the region on these time scales.

The spatial structure is also nonuniform (Fig. 3a). Magnitudes increase from southeast to northwest across the region, with smaller values $(1-3 \mathrm{~cm})$ observed along the United Arab Emirates, Qatar, Bahrain, and southern Iran, and larger values (3-5 cm) apparent off Saudi Arabia, Kuwait, Iraq, and northern Iran. This basin-scale structure could indicate a balance between local wind forcing-strengthening or weakening of the region's prevailing north-northwesterlies-and the combined effects of bottom friction and along-basin pressure gradient. Strongest amplitudes $(>5 \mathrm{~cm})$ are detected off Kuwait and Iraq. Values in this region are highest at the coast and decay offshore. Since depths become shallow and bathymetric gradients weak off Kuwait and Iraq relative to upstream along Iran (Fig. 1), these strong amplitudes may indicate coastal-wave amplification related to shoaling and broadening of the topography in this region (e.g., Hughes et al. 2019). It is also possible, as the region is adjacent to the mouths of the Tigris, Euphrates, and Karun Rivers, that trapped $\zeta$ signals driven by buoyant river discharge also come into play (e.g., Piecuch et al. 2018a). There is also spatial structure in the amount of local data variance explained by this mode: whereas $50 \%-80 \%$ of local $\zeta$ data variance is explained over the interior in the northwestern Persian Gulf, $<30 \%$ is explained in the southwest off Qatar, Bahrain, and the United Arab Emirates (Fig. 3b). This suggests important local-scale $\zeta$ variability along the southwest coast that is unrelated to the broader-scale behavior resolved by this mode. ${ }^{7}$

\footnotetext{
${ }^{7}$ Indeed, the second EOF mode (not shown), which explains $8 \%$ of the data variance, captures some of the variability in these areas. This mode exhibits amplitudes $>5 \mathrm{~cm}$ and explains $>30 \%$ of the data variance off western Qatar, around Bahrain, and along southeastern Saudi Arabia, whereas amplitudes of $2-3 \mathrm{~cm}$ and variances explained of $5 \%-30 \%$ are apparent in the southern shallows off the United Arab Emirates. Since it is tangential to our focus, we do not pay further attention to this mode, other than to posit that — due to the region's broad, shallow depths (Fig. 1) - it may arise from a balance between local winds and bottom friction.
}

The $\zeta$ response to surface forcing is often described in terms of barotropic (depth independent) and baroclinic (depth dependent) adjustments (e.g., Vinogradova et al. 2007). Given the latitude of the Persian Gulf, and the spatiotemporal scales under investigation, basic scaling arguments (Gill and Niiler 1973; Piecuch et al. 2019) suggest that this mode of $\zeta$ variation should be essentially barotropic in nature. For a purely barotropic ocean response, changes in sea level (or subsurface pressure) are mirrored by changes in ocean bottom pressure (Bingham and Hughes 2008; Vinogradova et al. 2007). Hence, if the leading mode of $\zeta$ variability from altimetry (Figs. 3 and 4 ) reflects a predominantly barotropic response, then similar $R_{m}$ variability should be apparent in GRACE.

To test this hypothesis, we apply EOF analysis to the GRACE $R_{m}$ grids over the Persian Gulf. The results are shown in Figs. 4 and 5. The leading mode, which explains $88 \%$ of the intraseasonal GRACE data variance in the Persian Gulf, shows a single-signed spatial pattern, such that variability increases from $1-2 \mathrm{~cm}$ in the southeastern Persian Gulf to $3-4 \mathrm{~cm}$ in the northwest (Fig. 5a). Relatively more local $R_{m}$ data variance is explained $(>80 \%)$ to the north and west, while comparatively less is explained $(50 \%-70 \%)$ in the southeast (Fig. 5b). These patterns from GRACE are qualitatively similar to those from altimetry, but there are quantitative differences (cf. Figs. 3 and 5). For example, the mode from altimetry exhibits larger amplitudes and richer, more detailed spatial structures than the mode from GRACE (Figs. 3a and 5a), whereas the leading GRACE mode explains relatively more data variance compared to the leading altimetry mode (Figs. $3 b$ and 5b). These discrepancies probably partly reflect the coarser resolution (and reduced effective spatial degrees of freedom) of GRACE but could also indicate baroclinic processes or data errors (e.g., residual leakage of terrestrial signals into the GRACE ocean grids).

Such differences notwithstanding, results in Figs. 3 and 5 suggest that GRACE and altimetry capture facets of the same underlying mode of intraseasonal variation. This suggestion is corroborated by the principal components of the leading EOF modes determined from GRACE and altimetry, which are highly correlated (correlation coefficient of $\sim 0.7$; Fig. 4 ). We also apply maximum covariance analysis (MCA) jointly to 

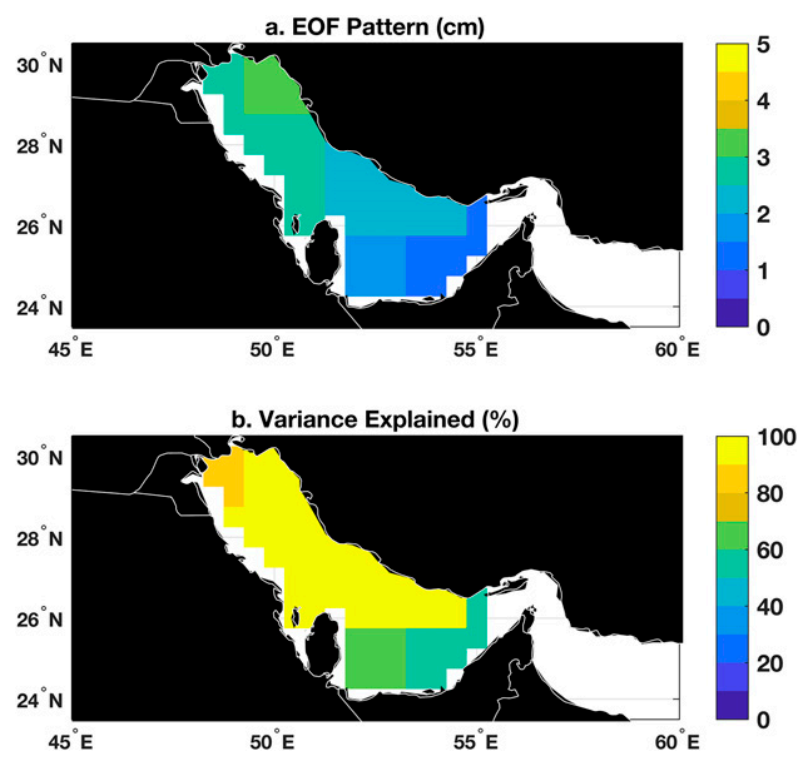

FIG. 5. (a) Spatial pattern (eigenvector) of the first $R_{m}$ EOF mode across the Persian Gulf from intraseasonal GRACE data (units are $\mathrm{cm}$ ). (b) Local $R_{m}$ variance explained by the first EOF mode (units are percent of total variance).

altimetry $\zeta$ and GRACE $R_{m}$ data, whereby the eigenvalues and eigenvectors of the cross-covariance matrix between the two datasets are determined (von Storch and Zwiers 1999). The leading eigenvectors and principal components determined jointly through MCA are identical to those determined separately through EOF analysis, and the gravest MCA mode explains $>99 \%$ of the joint covariance between altimetry and GRACE data (not shown). This suggests that the leading modes of regional $\zeta$ and $R_{m}$ variation are coupled to one another and reflect a dominant barotropic response.

\section{Forcing mechanisms and ocean dynamics}

In the previous section, we established a basinwide barotropic variation of the Persian Gulf on intraseasonal time scales. Here we use analytical theory, linear regression, and correlation analysis to identify the forcing and dynamics responsible for this mode.

\section{a. Linear barotropic model}

The leading mode of intraseasonal variability identified previously exhibits higher-order spatial structure (Figs. 3 and 5). However, the lowest-order spatial feature is that of a horizontally uniform fluctuation. For example, the time series of intraseasonal $\bar{\zeta}$ from altimetry explains $93 \%$ of the variance associated with the first altimetric EOF mode (Figs. 2-4). Thus, we formulate a linear model for a horizontally uniform barotropic variation of the Persian Gulf. Our formulation largely follows Volkov et al. (2016), who use a similar model to consider $\zeta$ in the Black Sea. The equations for conservation of volume within the Persian
Gulf and conservation of momentum along the Strait of Hormuz are

$$
\begin{aligned}
S \bar{\zeta}_{t} & =S \bar{q}+\frac{S}{\rho g} \bar{p}_{t}+v W H, \quad \text { and } \\
v_{t} & =-g \zeta_{y}+\frac{1}{\rho H} \tau-\frac{r}{H} v .
\end{aligned}
$$

Here, $S$ is surface area of the Persian Gulf; the overbar is a spatial average over the Persian Gulf; $q$ is precipitation plus runoff minus evaporation; $p$ is barometric pressure; $v$ is average velocity along the Strait of Hormuz into the Persian Gulf (positive values increase the volume of the Persian Gulf); $W$ and $H$ are the width and depth of the Strait of Hormuz, respectively; $\tau$ is wind stress along the Strait of Hormuz (positive in the direction of the Persian Gulf); $r$ is a constant friction coefficient; $g$ is gravity; $\rho$ is seawater density; and subscripts $t$ and $y$ denote partial differentiation in time and the along-strait direction, respectively. Note that since we express Eqs. (1) and (2) in terms of $\zeta$, forcing by $p$ appears in the continuity equation rather than in the momentum equation, and takes on a form analogous to the $q$ forcing, such that, as noted by Gill (1982), forcing by a depression of $10 \mathrm{mb}$ would be canceled out by $10 \mathrm{~cm}$ of precipitation (cf. also Ponte 2006). All symbols are described in Table 3, and representative values are given when appropriate.

We assume $\zeta, v, q, p$, and $\tau$ take wave solutions of the form $\exp (-i \omega t)$ with angular frequency $\omega$ and $i \doteq \sqrt{-1}$. Integrating the momentum equation over the length $L$ of the Strait of Hormuz, and rearranging to solve for $\bar{\zeta}$ gives

$\bar{\zeta}=\left[\zeta_{0}+\frac{L}{\rho g H} \tau+\frac{(\lambda-i \omega)}{\sigma^{2}} \bar{q}-i \omega \frac{(\lambda-i \omega)}{\sigma^{2}} \frac{\bar{p}}{\rho g}\right] /\left[1-\frac{\omega^{2}}{\sigma^{2}}-i \frac{\lambda \omega}{\sigma^{2}}\right]$,

where $\zeta_{0}$ represents $\zeta$ at the boundary outside the Strait of Hormuz in the Gulf of Oman, and we define $\sigma^{2} \doteq W H g / S L$ and $\lambda \doteq r / H$. Physically, $1 / \lambda$ is a friction time scale and $1 / \sigma$ is a Helmholtz resonance time scale determined by the shape of the Persian Gulf and Strait of Hormuz. (We determine that $1 / \sigma \approx 15 \mathrm{~h}$, which is small compared to the intraseasonal time scales of interest, so we do not expect a resonant response). Equivalently, we can write Eq. (3) in the polar complex plane as

$$
\begin{aligned}
\bar{\zeta}= & z_{\zeta_{0}} \exp \left(i \theta_{\zeta_{0}}\right) \zeta_{0}+z_{\tau} \exp \left(i \theta_{\tau}\right) \tau+z_{\bar{q}} \exp \left(i \theta_{\bar{q}}\right) \bar{q} \\
& +z_{\bar{p}} \exp \left(i \theta_{\bar{p}}\right) \bar{p}
\end{aligned}
$$

where

$$
\begin{aligned}
\theta_{\zeta_{0}} & \doteq \arctan \left(\frac{\lambda \omega}{\sigma^{2}-\omega^{2}}\right) \\
z_{\zeta_{0}} & \doteq\left[\left(1-\frac{\omega^{2}}{\sigma^{2}}\right)^{2}+\left(\frac{\lambda \omega}{\sigma^{2}}\right)^{2}\right]^{-1 / 2},
\end{aligned}
$$


TABLE 3. Descriptions of and, where applicable, reasonable values for variables and parameters in governing equations. Values of the friction coefficient $r$ are uncertain. Previous studies variously use values ranging from as small as $4 \times 10^{-5} \mathrm{~m} \mathrm{~s}^{-1}$ (e.g., Ponte 1994 ) to as large as $2 \times 10^{-2} \mathrm{~m} \mathrm{~s}^{-1}$ (e.g., Ponte 2006). Values in the table represent a reasonable, physically plausible range based on choices made in previous studies.

\begin{tabular}{clc}
\hline \hline Parameter & \multicolumn{1}{c}{ Description } & Value \\
\hline$\zeta$ & Ocean dynamic sea level & - \\
$\tau$ & Mean wind stress along Strait of Hormuz & - \\
$q$ & Surface freshwater flux & - \\
$p$ & Barometric pressure & - \\
$\zeta_{0}$ & Ocean dynamic sea level in Gulf of Oman & - \\
$S$ & Spatial average over Persian Gulf & $2.2 \times 10^{5} \mathrm{~km}^{2}$ \\
$H$ & Surface area of Persian Gulf & $30 \mathrm{~m}$ \\
$L$ & Average depth of Persian Gulf & $400 \mathrm{~km}$ \\
$W$ & Length of Strait of Hormuz & $100 \mathrm{~km}^{-2}$ \\
$g$ & Width of Strait of Hormuz & $9.81 \mathrm{~m} \mathrm{~s}^{-2}$ \\
$r$ & Gravitational acceleration & $1029 \mathrm{~kg} \mathrm{~m}^{-3}$ \\
$\lambda$ & Ocean density & $1 \times 10^{-3}-1 \times 10^{-2} \mathrm{~m} \mathrm{~s}^{-1}$ \\
& Friction coefficient & $1.8 \times 10^{-5} \mathrm{~s}^{-1}$ \\
\end{tabular}

$\theta_{\tau} \doteq \arctan \left(\frac{\lambda \omega}{\sigma^{2}-\omega^{2}}\right)$

$z_{\tau} \doteq\left[\left(1-\frac{\omega^{2}}{\sigma^{2}}\right)^{2}+\left(\frac{\lambda \omega}{\sigma^{2}}\right)^{2}\right]^{-1 / 2}\left(\frac{L}{\rho g H}\right)$

$\theta_{\bar{q}} \doteq \arctan \left(\frac{\lambda \omega}{\sigma^{2}}-\frac{\omega}{\lambda}+\frac{\omega^{3}}{\sigma^{2} \lambda}\right)$

$z_{\bar{q}} \doteq \frac{\lambda}{\sigma^{2}}\left[1+\left(\frac{\lambda \omega}{\sigma^{2}}-\frac{\omega}{\lambda}+\frac{\omega^{3}}{\sigma^{2} \lambda}\right)^{2}\right]^{1 / 2}\left[\left(1-\frac{\omega^{2}}{\sigma^{2}}\right)^{2}+\left(\frac{\lambda \omega}{\sigma^{2}}\right)^{2}\right]^{-1}$,

$\theta_{\bar{p}} \doteq \arctan \left[\left(\frac{\omega}{\lambda}-\frac{\omega^{3}}{\lambda \sigma^{2}}-\frac{\omega \lambda}{\sigma^{2}}\right)^{-1}\right], \quad$ and

$z_{\bar{p}} \doteq \frac{1}{\rho g} \frac{\lambda \omega}{\sigma^{2}}\left[1+\left(\frac{\omega}{\lambda}-\frac{\lambda \omega}{\sigma^{2}}-\frac{\omega^{3}}{\sigma^{2} \lambda}\right)^{2}\right]^{1 / 2}\left[\left(1-\frac{\omega^{2}}{\sigma^{2}}\right)^{2}+\left(\frac{\omega \lambda}{\sigma^{2}}\right)^{2}\right]^{-1}$.

In other words, according to Eq. (4), $\bar{\zeta}$ is a linear superposition of the $\zeta_{0}, \tau, \bar{q}$, and $\bar{p}$ forcing terms, each scaled by an amount $z_{j}$ and rotated through a phase $\theta_{j}$, where $j \in\left\{\zeta_{0}, \tau, \bar{q}, \bar{p}\right\}$. We estimate theoretical values for the scaling factors $z_{j}$ and phase angles $\theta_{j}$ by averaging Eqs. (5)(12) over the $\omega$ range from $2 \pi /(6$ months $)$ to $2 \pi /(2$ months $)$ using numerical values for the scalar coefficients $\lambda, \sigma, L, \rho$, $g$, and $H$ from Table 3 . These theoretical values are tabulated in Table 4.

\section{b. Multiple linear regression analysis}

To test whether the model described by Eqs. (1)-(12) is informative for understanding observed intraseasonal $\bar{\zeta}$ variability, we perform a multiple linear regression. We model $\bar{\zeta}$ from altimetry as

$$
\begin{aligned}
\bar{\zeta}= & a_{\zeta_{0}} \zeta_{0}+b_{\zeta_{0}} \mathcal{H}\left(\zeta_{0}\right)+a_{\tau} \tau+b_{\tau} \mathcal{H}(\tau)+a_{\bar{q}} \bar{q}+b_{\bar{q}} \mathcal{H}(\bar{q}) \\
& +a_{\bar{p}} \bar{p}+b_{\bar{p}} \mathcal{H}(\bar{p})+\varepsilon
\end{aligned}
$$

where $\mathcal{H}$ is the Hilbert transform, the $a_{j}$ and $b_{j}$ are real constants, and $\varepsilon$ is the residual. We include Hilbert transforms of the various forcings in the regression to allow for possible phase lags between the forcing and the response, as indicated by Eq. (4). We estimate the $z_{j}$ and $\theta_{j}$ from Eq. (4) from the $a_{j}$ and $b_{j}$ in Eq. (13) using properties of Hilbert transforms and trigonometric identities as

$$
\theta_{j}=\arctan \left(b_{j} / a_{j}\right), \quad \text { and }
$$

TABLE 4. Estimates of the scaling coefficients $\left(z_{j}\right)$ and phase angles $\left(\theta_{j}\right)$ in Eq. (4). The theoretical ranges are determined by averaging Eqs. (5)-(12) over the range from $\omega=2 \pi /(6$ months $)$ to $2 \pi /(2$ months $)$ using the constant values for $\sigma, L, \rho, g$, and $H$ and the minimum and maximum values for $\lambda$ tabulated in Table 3. Empirical values are determined through multiple linear regression involving $\bar{\zeta}$ and $\zeta_{0}$ from altimetry, $\tau$ and $\bar{p}$ from ERA-Interim, and $\bar{q}$ based on JRA55-do, GPCP, and OAFlux and are presented as $95 \%$ confidence intervals estimated based on bootstrapping. Scaling coefficients are given to one decimal point, and phase angles are rounded to the nearest degree.

\begin{tabular}{lcc}
\hline \hline Parameter (units) & Theoretical range & Empirical value \\
\hline$z_{\zeta_{0}}($ unitless) & $0.8-1.0$ & $1.0 \pm 0.2$ \\
$\theta_{\zeta_{0}}\left({ }^{\circ}\right)$ & $5-38$ & $5 \pm 10$ \\
$z_{\tau}\left(\mathrm{m} \mathrm{Pa}^{-1}\right)$ & $1.0-1.3$ & $1.5 \pm 0.5$ \\
$\theta_{\tau}\left({ }^{\circ}\right)$ & $5-38$ & $30 \pm 25$ \\
$z_{\bar{q}}($ days $)$ & $1.2-9.0$ & $9.4 \pm 3.7$ \\
$\theta_{\bar{q}}\left({ }^{\circ}\right)$ & $3-38$ & $30 \pm 27$ \\
$z_{\bar{p}}\left(\mathrm{~cm} \mathrm{mb} \mathrm{mb}^{-1}\right)$ & $0.1-0.5$ & $0.8 \pm 0.5$ \\
$\theta_{\bar{p}}\left({ }^{\circ}\right)$ & $56-87$ & $65 \pm 52$ \\
\hline
\end{tabular}



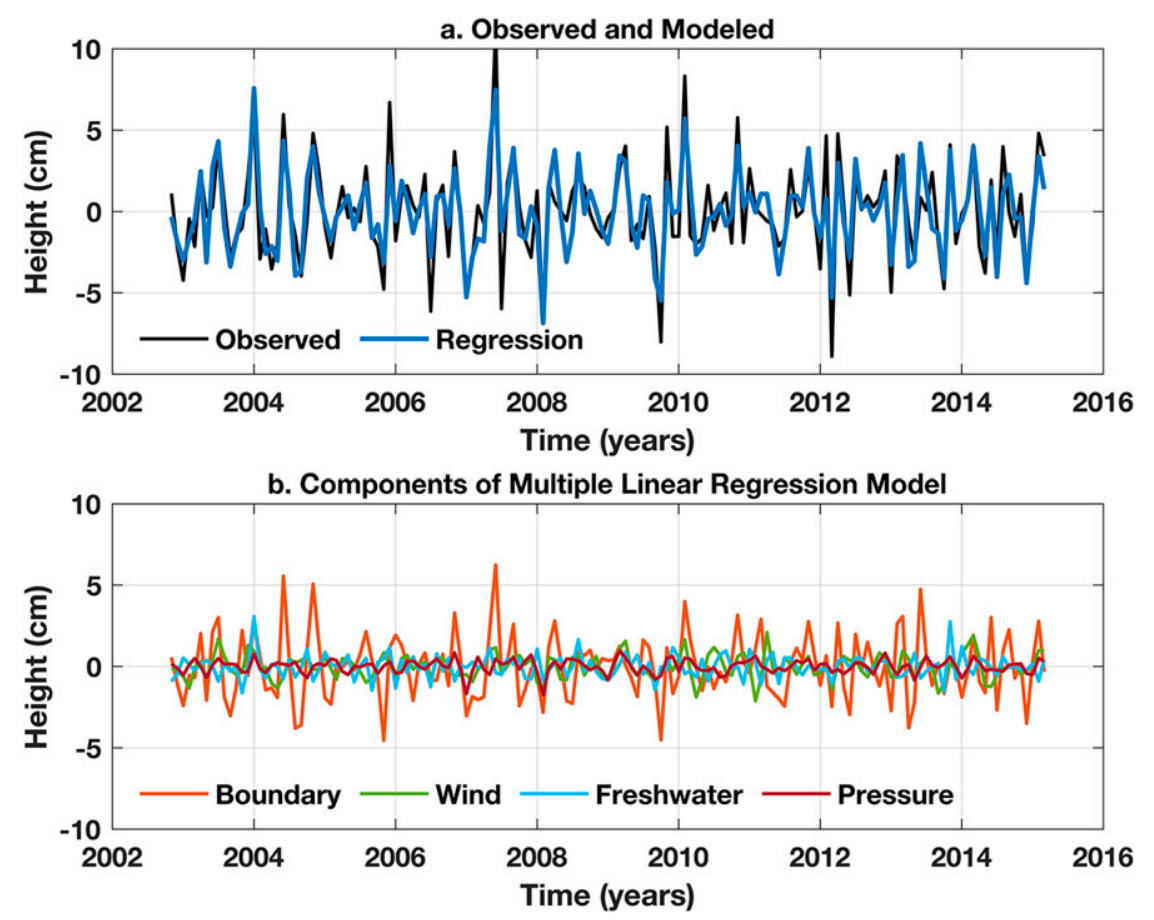

FIG. 6. (a) Time series of intraseasonal $\bar{\zeta}$ from satellite altimetry (black) and the results of the multiple linear regression model (blue) (units are $\mathrm{cm}$ ). (b) Breakdown of contributors to regression model—boundary forcing $\zeta_{0}$ (orange), wind stress $\tau$ (green), freshwater flux $\bar{q}$ (blue), and barometric pressure $\bar{p}$ (red) (units are $\mathrm{cm}$ ).

$$
z_{j}=\sqrt{a_{j}^{2}+b_{j}^{2}}
$$

We evaluate Eq. (13) using least squares. For $\zeta_{0}$, we use $\zeta$ from altimetry averaged over shallow regions $(<200 \mathrm{~m})$ of the northern Gulf of Oman outside the Strait of Hormuz $\left(57^{\circ}-60^{\circ} \mathrm{E}, 25^{\circ}-28^{\circ} \mathrm{N}\right)$. For $\tau$, we use along-strait wind stress $\left(315^{\circ} \mathrm{T}\right)$ from ERA-Interim averaged over the Strait of Hormuz $\left(54^{\circ}-57.8^{\circ} \mathrm{E}, 22.9^{\circ}-27.4^{\circ} \mathrm{N}\right)$. For $\bar{q}$, we use precipitation from GPCP plus river runoff from JRA55-do minus evaporation from OAFlux averaged over the Persian Gulf $\left(45^{\circ}-55^{\circ} \mathrm{E}, 24^{\circ}-32^{\circ} \mathrm{N}\right)$. For $\bar{p}$, we use barometric pressure from ERA-Interim averaged over the Persian Gulf $\left(48^{\circ}-\right.$ $\left.54.8^{\circ} \mathrm{E}, 24.4^{\circ}-29.6^{\circ} \mathrm{N}\right)$. Uncertainties are estimated using 10000 iterations of bootstrapping (Efron and Hastie 2016).

Results of the multiple linear regression are summarized in Fig. 6. The regression model [(13)] explains 70\% $\pm 9 \%(95 \%$ confidence interval) of the variance in the $\bar{\zeta}$ data (Fig. 6a). This suggests that Eqs. (1) and (2) represent the dominant physics, and that $\bar{\zeta}$ variability can be largely understood in terms of local surface forcing by $\tau, \bar{q}$, and $\bar{p}$ and nonlocal boundary forcing by $\zeta_{0}$. In Fig. $6 \mathrm{~b}$, we break down the relative contributions of the different forcing terms. The primary driver of $\bar{\zeta}$ is nonlocal forcing by $\zeta_{0}$, which explains $50 \% \pm$ $12 \%$ of the $\bar{\zeta}$ variance. Local forcing by $\tau, \bar{q}$, and $\bar{p}$ plays a secondary role. Individually, $\tau$ explains $16 \% \pm 9 \%, \bar{q}$ explains $5 \% \pm 9 \%$, and $\bar{p}$ explains $10 \% \pm 8 \%$ of the $\bar{\zeta}$ variance. Surface loading (the combination of $\bar{q}$ and $\bar{p}$ forcing) explains $14 \% \pm 11 \%$ of the variance in the data. Collectively, all three local forcing factors taken together account for $27 \% \pm 14 \%$ of the $\bar{\zeta}$ variance. ${ }^{8}$

Regression coefficients computed empirically from the data are consistent with values expected theoretically from first principles (Table 4). For example, the linear regression yields a scaling factor of $1.5 \pm 0.5 \mathrm{~m} \mathrm{~Pa}^{-1}$ and a phase angle of $30^{\circ} \pm 25^{\circ}$ between $\tau$ and $\bar{\zeta}$. This is consistent with the theoretical ranges of $1.0-1.3 \mathrm{~m} \mathrm{~Pa}^{-1}$ and $5^{\circ}-38^{\circ}$ anticipated from Eqs. (7) and (8). The regression analysis also suggests a substantial departure from the inverted-barometer response, manifested in a scaling of $0.8 \pm 0.5 \mathrm{~cm} \mathrm{mb}^{-1}$ and a phase of $65^{\circ} \pm 52^{\circ}$ between $\bar{p}$ and $\bar{\zeta}$. This overlaps with the ranges of $0.1-0.5 \mathrm{~cm} \mathrm{mb}^{-1}$ and $56^{\circ}-87^{\circ}$ expected from Eqs. (11) and (12). (Recall that the altimeter data have been adjusted for an inverted barometer and that our theory was developed for $\zeta$, which has the

\footnotetext{
${ }^{8}$ The variance contributions of the individual predictors are not entirely additive since they are not wholly independent and there is some correlation between them. However, the relative roles of the respective forcings can nevertheless be meaningfully estimated (albeit with uncertainty) because the least squares problem is generally well posed. After normalizing the predictors to unit variance, the condition number of their covariance matrix is 3.3 . This is on the same order as the range of 1.4-2.5 (99\% confidence interval) we determine through repeated simulations of four independent random, standard-normal time series (and their Hilbert transforms) with the same length as the observations (not shown).
} 


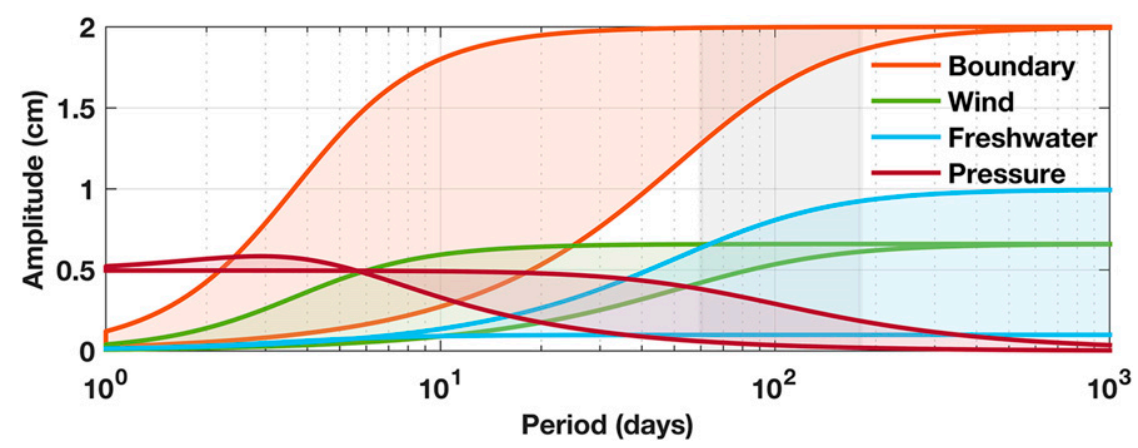

FIG. 7. Amplitude of $\bar{\zeta}$ response to boundary forcing $\zeta_{0}$ (orange), wind stress $\tau$ (green), freshwater flux $\bar{q}$ (blue), and barometric pressure $\bar{p}$ (red) as a function of period. Values are based on Eqs. (6), (8), (10) and (12) using parameter values from Table 3. Upper and lower lines are bounds determined by the range of friction coefficient $r$. See text for more details. Gray shading indicates intraseasonal periods of primary interest here.

inverted-barometer effect already removed.) This provides evidence that the results of the multiple linear regression indicate true causal relationships between forcing and response.

Regression results and analytical theory suggest that these relationships can be out of phase, such that the forcings lead the response by a significant amount (Table 4). To quantify the importance of out-of-phase behavior, we perform another multiple linear regression analysis, this time omitting Hilbert transforms and forcing by $p$ from the input [cf. Eq. (13)]. Physically, this alternative regression model assumes an equilibrium response, and corresponds to the steady state $(\omega \rightarrow 0)$ limit of the governing equations, namely [cf. Eq. (3)],

$$
\bar{\zeta}=\zeta_{0}+\frac{L}{\rho g h} \tau+\frac{\lambda}{\sigma^{2}} \bar{q} .
$$

This alternate model accounts for slightly less of the $\bar{\zeta}$ data variance $(62 \% \pm 10 \% ; 95 \%$ confidence interval $)$. This result demonstrates that a majority of the $\bar{\zeta}$ data variance explained by the original multiple linear regression model [Eq. (13)] is attributable to equilibrium processes and in-phase (or antiphase) relationships between the forcing and the response, but also that allowing for transient processes [the time derivatives in Eqs. (1) and (2)] and more general phase relationships between forcing and response leads to a modest, but significant, improvement in terms of explaining $\bar{\zeta}$ data variance.

To ascertain whether similar balances are expected at other periods, we consider the $\bar{\zeta}$ response from our model as a function of time scale. We multiply the frequency-dependent scale coefficients $\left[z_{j}\right.$ in Eqs. (6), (8), (10), and (12)] by a representative fluctuation in the respective forcing [cf. Eq. (4)]. We use $\left|\zeta_{0}\right|=2 \mathrm{~cm},|\tau|=0.005 \mathrm{~N} \mathrm{~m}^{-2},|\bar{q}|=1 \times 10^{-8} \mathrm{~m} \mathrm{~s}^{-1}$, and $|\bar{p}|=0.5 \mathrm{hPa}$ based on standard deviations computed from the data. Results are shown in Fig. 7. As demanded by Eqs. (6), (8), (10), and (12), the $\bar{\zeta}$ responses to $\zeta_{0}, \tau$, and $\bar{q}$ forcing increase with period, while the $\bar{\zeta}$ adjustment to $\bar{p}$ driving generally decreases with period. The precise rate at which the $\bar{\zeta}$ adjustment approaches its equilibrium response is dictated by friction and the region's shape, as represented by $\lambda$ and $\sigma$. Given the forcing amplitudes, $\bar{\zeta}$ variability is dominated by $\bar{p}$ forcing on time scales of a few days. On time scales of a few days to a few weeks, the influences of $\bar{p}, \tau$, and $\zeta_{0}$ on $\bar{\zeta}$ can be comparable, depending on the details of friction. At periods longer than a few weeks, forcing by $\zeta_{0}$ is the primary driver of $\bar{\zeta}$ variability. At all periods, $\zeta_{0}$ forcing is more influential than $\tau$ and $\bar{q}$ forcing. Thus, our findings on intraseasonal time scales are representative of the large-scale, low-frequency barotropic response of the Persian Gulf to external forcing more broadly. This suggests that similar dynamical balances would be obtained in studies of the Persian Gulf over longer time scales. But note that our results are a function of the forcing amplitudes, geometry of the region, and friction. For example, assuming similar friction values and forcing scales, $\tau$ and $\bar{q}$ forcing would become relatively more important compared to $\zeta_{0}$ forcing for a marginal sea with a larger surface area than the Persian Gulf that connects to the open ocean through a strait that is longer, shallower, and narrower than the Strait of Hormuz.

\section{c. Relation to Indian Ocean circulation and climate, and potential predictability}

Nonlocal forcing by $\zeta_{0}$ is the most important contributor to $\bar{\zeta}$ variability (Figs. $6 \mathrm{~b}$ and 7 ). What is the nature of these fluctuations at the boundary in the Gulf of Oman? How do they relate to larger-scale circulation and climate? To clarify their origin, we compute correlation coefficients between $\zeta_{0}$ and either $\zeta$ or its Hilbert transform $\mathcal{H}(\zeta)$ at every altimetric grid point over the equatorial and north Indian Ocean. Correlations between $\zeta_{0}$ and $\zeta$ identify regions where $\zeta$ is in phase or antiphase (i.e., $180^{\circ}$ out of phase) with $\zeta_{0}$, whereas correlations between $\zeta_{0}$ and $\mathcal{H}(\zeta)$ indicate regions where $\zeta$ is in quadrature $\left(90^{\circ}\right.$ out of phase) or antiquadrature $\left(270^{\circ}\right.$ out of phase) with $\zeta_{0}$.

In general, $\zeta_{0}$ is uncorrelated with $\zeta$ and $\mathcal{H}(\zeta)$ away from the coast and the equator (Figs. 8 and 9 ), suggesting that $\zeta_{0}$ is unrelated to the dominant $\zeta$ variability in these open-ocean 


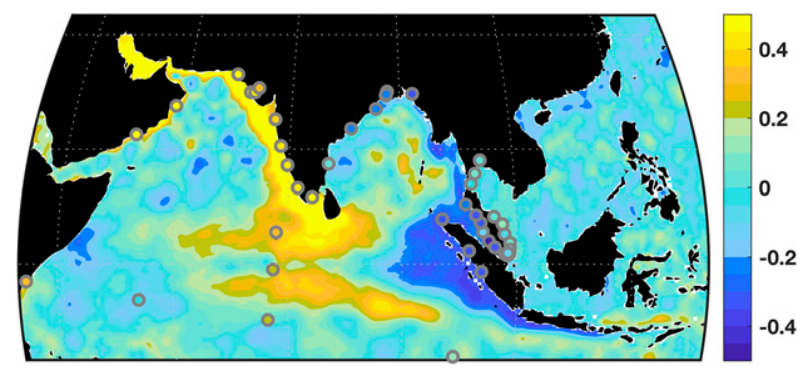

FIG. 8. Shading represents correlation coefficients between Gulf of Oman $\zeta_{0}$ and $\zeta$ from altimetry over the equatorial and north Indian Ocean. Dots are the same, but based on $\zeta$ from available tide gauges. Light shading indicates values that are not distinguishable from zero at the $95 \%$ confidence level (assuming 100 degrees of freedom).

regions. However, we observe patterns of significant correlation and anticorrelation along the coast and equator. For example, $\zeta_{0}$ is correlated with $\zeta$ along Pakistan, western India, and Sri Lanka; correlated with $\mathcal{H}(\zeta)$ along eastern India, Bangladesh, and Myanmar; correlated with $\mathcal{H}(\zeta)$ and anticorrelated with $\zeta$ along Thailand, Malaysia, and Sumatra; and anticorrelated with $\mathcal{H}(\zeta)$ along the western equatorial Indian Ocean between Somalia and the Maldives (Figs. 8 and 9). Similar correlation patterns are observed between $\zeta_{0}$ and available tide gauge data over the equatorial and north Indian Ocean (Fig. 8). Given the gaps in the data, we do not compute Hilbert transforms from the tide gauge records. [Note also that we computed correlations with altimetry more globally over the ocean but did not observe large-scale regions of significant correlation between $\zeta_{0}$ and $\zeta$ or $\mathcal{H}(\zeta)$ outside of the equatorial and north Indian Ocean that suggested viable causal connections (not shown)].

These patterns suggest wave propagation along equatorial and coastal waveguides. For example, the correlation between $\zeta_{0}$ and $\mathcal{H}(\zeta)$ along Bangladesh suggests that $\zeta_{0}$ lags $\zeta$ in this region by $90^{\circ}$ (one-quarter of a period), whereas anticorrelation between $\zeta_{0}$ and $\mathcal{H}(\zeta)$ in the western equatorial Indian Ocean hints that regional $\zeta$ leads $\zeta_{0}$ by $270^{\circ}$ (three-quarters of a period). Supposing propagation is eastward along the equator and counterclockwise along the coast (in the Northern Hemisphere), and assuming intraseasonal periods of 60 180 days, we estimate that these phase leads and lags imply propagation speeds of $\sim 1-3 \mathrm{~m} \mathrm{~s}^{-1}$. These values are consistent with basic expectations for equatorial waves and coastally trapped waves (e.g., Gill 1982; Hughes et al. 2019). Indeed, past studies argue that low-latitude wind forcing associated with the Madden-Julian oscillation (MJO) and phases of the monsoon excite wave responses that effect intraseasonal sea level variability along Sumatra and Java (Iskandar et al. 2005), the Bay of Bengal (Cheng et al. 2013), and India and Sri Lanka (Suresh et al. 2013; Dhage and Strub 2016). Our results reinforce these past findings and suggest that these nonlocal forcing effects mediated by large-scale wave responses continue on and are communicated to the Persian Gulf.

We perform a similar analysis with GRACE data. Correlations between $\zeta_{0}$ and either GRACE $R_{m}$ or its Hilbert transform $\mathcal{H}\left(R_{m}\right)$ over the Indian Ocean are shown in Fig. 10. While there

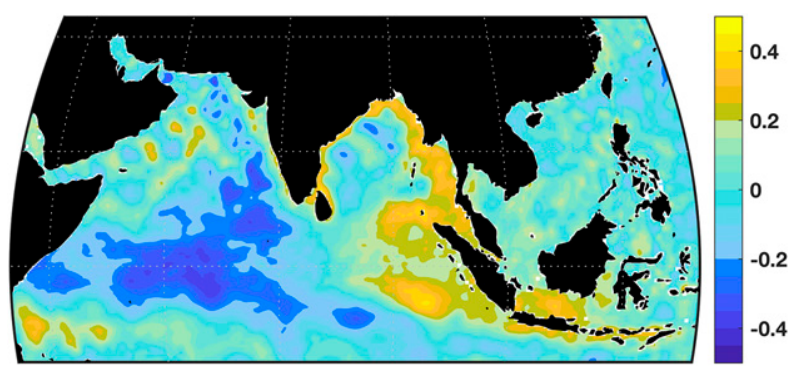

FIG. 9. Shading represents correlation coefficients between Gulf of Oman $\zeta_{0}$ and $\mathcal{H}(\zeta)$ from altimetry over the equatorial and north Indian Ocean. Light shading indicates values that are not distinguishable from zero at the $95 \%$ confidence level (assuming 100 degrees of freedom).

is essentially no meaningful correlation anywhere between $\zeta_{0}$ and $\mathcal{H}\left(R_{m}\right)$, there is significant correlation between $\zeta_{0}$ and GRACE $R_{m}$ broadly over much of the Indian Ocean (Fig. 10). This suggests that $\zeta_{0}$ is also related to a basin-scale equilibrium response in addition to the more transient wave adjustments trapped to the coast and the equator suggested by the altimetry data (Figs. 8 and 9). Indeed, the correlation pattern between $\zeta_{0}$ and $R_{m}$ (Fig. 10a) is similar to the spatial structure of the intraseasonal fluctuation of the Indian Ocean identified by Rohith et al. (2019) based on data from bottom-pressure recorders, GRACE, and a general circulation model. They argue that wind-curl fluctuations at 30-80-day periods over the Wharton basin associated with the MJO excite planetary and topographic Rossby wave responses that lead to a basinwide barotropic variation that is confined to the Indian Ocean by bathymetric contours. Our results provide observational evidence that this large-scale intraseasonal fluctuation affects variability not only over the deep Indian Ocean but also within its shallow marginal seas.

Wave propagation apparent in Figs. 8 and 9 hints that $\zeta_{0}$ variability may be predictable to some extent. That is, armed with upstream $\zeta$ information, it may be possible to anticipate $\zeta_{0}$ variance in advance. To test this possibility, we compute lagged correlation coefficients between $\zeta_{0}$ and $\zeta$ at earlier times over the equatorial and north Indian Ocean. Results are shown in Figs. 11 and 12 for lead times of 1 and 2 months, respectively. Considering a 1 -month lead time, we find positive correlations between $\zeta_{0}$ and $\zeta$ upstream along the Indian subcontinent and Maritime Continent, from eastern India to Sumatra, and negative correlations over the western equatorial Indian Ocean between Somalia and the Maldives (Fig. 11). Indeed, the pattern of correlation between $\zeta_{0}$ and $\zeta 1$ month earlier is similar to the structure of correlation between $\zeta_{0}$ and $\mathcal{H}(\zeta)$ (cf. Figs. 9 and 11), suggesting a dominant time scale of $\sim 4$ months. Values of 0.4-0.5 are apparent off Myanmar and Sumatra (Fig. 11), hinting that $16 \%-25 \%$ of the variance in $\zeta_{0}$ can be predicted from $\zeta$ knowledge in these regions 1 month earlier. Considering a lead time of 2 months, we observe that $\zeta_{0}$ and $\zeta$ are largely uncorrelated, except for along Pakistan, western India, and Sri Lanka, where negative coefficients between -0.3 and -0.4 are seen. This implies that $9 \%-16 \%$ of the $\zeta_{0}$ variance can be predicted from $\zeta$ observations along 
a. Correlation with GRACE
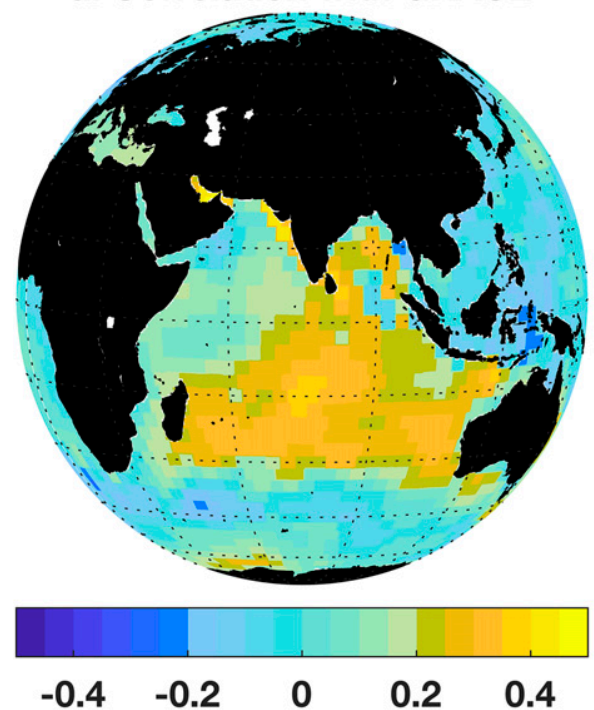

\section{b. Correlation with Hilbert Transform}

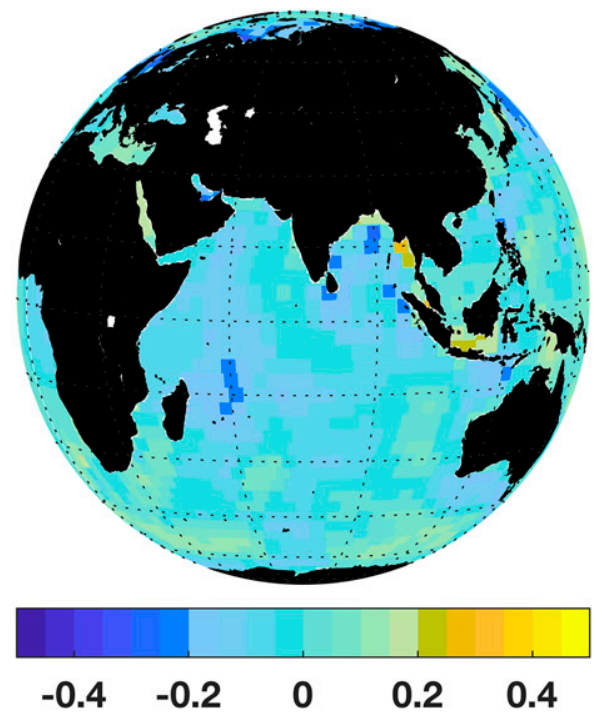

FIG. 10. Correlation coefficient between Gulf of Oman $\zeta_{0}$ and either (a) $R_{m}$ from GRACE or (b) $\mathcal{H}\left(R_{m}\right)$ over the Indian Ocean. Light shading indicates values that are not distinguishable from zero at the $95 \%$ confidence level (assuming 100 degrees of freedom).

this coastline 2 months earlier. Considering lead times of 3 months and longer, we detect no significant correlations between $\zeta_{0}$ and $\zeta$ elsewhere (not shown), indicating that there is little skill in predictions of intraseasonal $\zeta_{0}$ variability more than 2 months into the future from wave characteristics and ocean memory alone. Considering the available tide gauge records in the equatorial and north Indian Ocean, we obtain similar patterns of lagged correlations (Figs. 11 and 12).

\section{Summary and discussion}

We studied intraseasonal variability in ocean dynamic sea level ( $\zeta$ ) over the Persian Gulf during 2002-15 using satellite observations and other data (Figs. 1 and 2). Intraseasonal $\zeta$ variability in the Persian Gulf manifests in a basinwide, vertically coherent mode of fluctuation (Figs. 3-5). This largescale mode is related to freshwater flux and barometric pressure over the Persian Gulf, wind stress along the Strait of Hormuz, and nonlocal forcing embodied in $\zeta$ variations at the boundary in the Gulf of Oman (Figs. 6 and 7). The $\zeta$ boundary condition shows rich correlation patterns with altimetry data upstream along the Indian subcontinent, Maritime Continent, and equatorial Indian Ocean (Figs. 8 and 9), and with GRACE data broadly over the Indian Ocean (Fig. 10), suggesting an intimate connection between intraseasonal $\zeta$ variability in the Persian Gulf and large-scale circulation and climate in the equatorial and north Indian Ocean mediated by equatorial-, Rossby-, and coastal-wave processes identified previously (Cheng et al. 2013; Dhage and Strub 2016; Iskandar et al. 2005; Oliver and Thompson 2010; Rohith et al. 2019; Suresh et al. 2013, 2016; Waliser et al. 2003a,b). Our results indicate that some intraseasonal $\zeta$ variance in the Persian Gulf may be predictable a month or so in advance from upstream observations and the physics of coastal wave propagation and ocean memory (Figs. 11 and 12).

Our results establish the dominant magnitudes, scales, and mechanisms of intraseasonal sea level variability in the Persian Gulf, and thus build on findings from past works that emphasize seasonal cycles and decadal trends (Al-Subhi 2010; Alothman et al. 2014; Ayhan 2020; El-Gindy 1991; El-Gindy and Eid 1997; Hassanzadeh et al. 2007; Hosseinibalam et al. 2007; Sharaf El Din 1990; Siddig et al. 2019; Sultan et al. 1995a, 2000). Our study demonstrates that GRACE satellite retrievals are informative for interrogating coastal sea level over a semienclosed marginal sea, thereby complementing previous efforts that demonstrate the value of GRACE data in other marginal seas (Feng et al. 2012, 2014; Fenoglio-Marc et al. 2006, 2012; Landerer and Volkov 2013; Loomis and Luthcke 2017; Piecuch and Ponte 2015; Piecuch et al. 2018b;

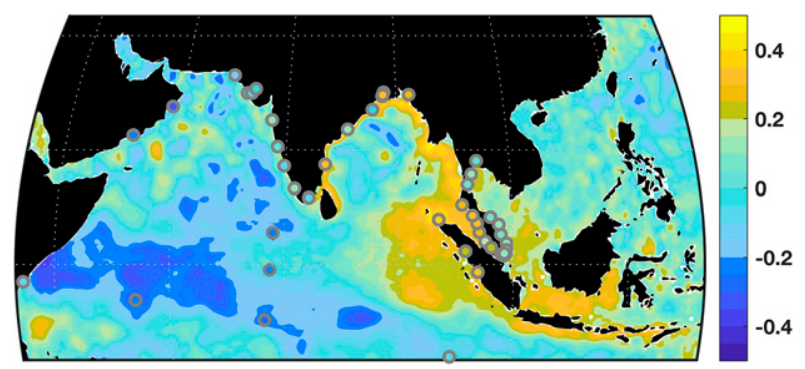

FIG. 11. Shading represents correlation coefficients between Gulf of Oman $\zeta_{0}$ and altimetric $\zeta$ elsewhere over the equatorial and north Indian Ocean 1 month earlier (i.e., $\zeta_{0}$ is lagging $\zeta$ elsewhere). Dots are the same, but based on $\zeta$ from available tide gauges. Light shading indicates values that are not distinguishable from zero at the $95 \%$ confidence level (assuming 100 degrees of freedom). 


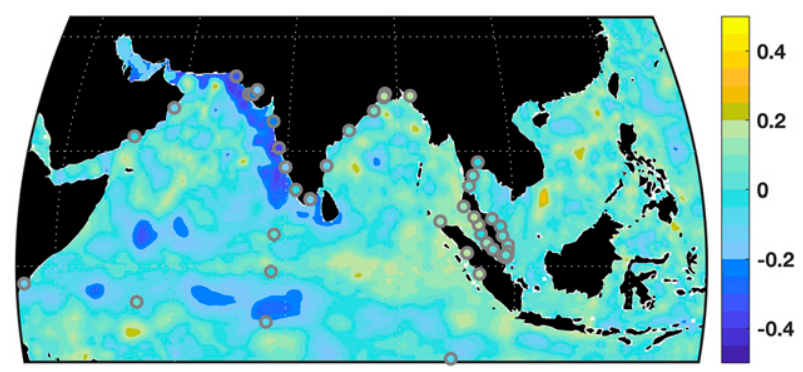

FIG. 12. Shading represents correlation coefficients between Gulf of Oman $\zeta_{0}$ and altimetric $\zeta$ elsewhere over the equatorial and north Indian Ocean 2 months earlier (i.e., $\zeta_{0}$ is lagging $\zeta$ elsewhere). Dots are the same, but based on $\zeta$ from available tide gauges. Light shading indicates values that are not distinguishable from zero at the $95 \%$ confidence level (assuming 100 degrees of freedom).

Tregoning et al. 2008; Wahr et al. 2014; Wang et al. 2015; Wouters and Chambers 2010), and encouraging further exploration of GRACE data in the Persian Gulf at other time scales.

Intraseasonal $\zeta$ variability in the Persian Gulf is coupled to variable volume exchanges between the Persian Gulf and Arabian Sea through the Strait of Hormuz. Observations of the time-variable transport through the Strait of Hormuz are limited to short field campaigns (e.g., Johns et al. 2003). Therefore, it is informative to consider the transport variability implied by data here and permitted by our model. Based on volume conservation [Eq. (1)], we make a rough estimate of the variable transport using our time series of surface freshwater flux and time derivatives of $\zeta$ and air pressure (not shown). The standard deviation of the transport estimate is $2.7 \times 10^{3} \mathrm{~m}^{3} \mathrm{~s}^{-1}$. In relative terms, this represents a departure of $19 \%-28 \%$ from the steady state transport required to balance canonical values for the average evaporation over the Persian Gulf of 1.4$2 \mathrm{~m} \mathrm{yr}^{-1}$ (Privett 1959; Ahmad and Sultan 1991; Johns et al. 2003). These transport fluctuations arise from subtle velocity variations averaged over the width and depth of the Strait of Hormuz of only $\sim 0.9 \mathrm{~mm} \mathrm{~s}^{-1}$. An interrogation of our model equations [Eqs. (1) and (2)] suggests that these variations in transport result mainly from a combination of local surface freshwater flux and nonlocal forcing at the boundary over the Gulf of Oman (see the appendix).

This investigation advances knowledge of sea level variability in the Persian Gulf. It also paves the way for future studies, pointing to open questions. For example, we developed and tested a theory for a horizontally uniform fluctuation of the Persian Gulf. However, the leading mode of intraseasonal $\zeta$ variability in the region exhibits spatial structure, such that magnitudes are larger in the northwest and smaller in the southeast of the Persian Gulf (Figs. 3 and 5). We hypothesized that this spatial structure could arise from local surface forcing or topographic effects on coastal-wave propagation. Future studies based on high-resolution ocean models should test these hypotheses and identify the controls on spatial structure.

It also remains to quantify whether baroclinic effects and steric processes contribute to the dominant intraseasonal $\zeta$ variability in the Persian Gulf. Vertical density stratification in the region is stronger during summer than during winter (Reynolds 1993), and offshore bathymetric gradients are more dramatic to the east along Iran than to the north, west, and south along other Persian Gulf nations (Fig. 1). Coastal wave theory (Hughes et al. 2019, and references therein) suggests that such conditions favor barotropic (topographic) wave $\zeta$ adjustment in wintertime or along the coast from Iraq to Oman, but that baroclinic (Kelvin) wave $\zeta$ response may be relevant along the coast of Iran in summertime. Local surface heat fluxes could also affect important variations in density and steric height. For example, fluctuations in evaporation of $\pm 1 \times 10^{-8} \mathrm{~m} \mathrm{~s}^{-1}$ (cf. Figs. 6 and 7) correspond to variations in latent heat flux of $\pm 25 \mathrm{~W} \mathrm{~m}^{-2}$ [see Eq. (4a) in Large and Yeager 2004], which, if sustained for periods of 60-180 days, would result in fluctuations in steric height of 2-5 mm (see Eq. (8) in Vivier et al. 1999). Steric changes were not estimated due to the lack of continuous hydrographic records in the Persian Gulf (e.g., Good et al. 2013). However, future studies could explore this topic by comparing differences between altimetry and GRACE, which are potentially informative of steric processes, to sea level changes anticipated from the passive response to local surface heat flux (e.g., Cabanes et al. 2006), or sea surface temperature data assuming that ocean temperature variations are vertically coherent (e.g., Meyssignac et al. 2017).

We determined that dynamic response to barometric pressure and freshwater flux is a secondary but nevertheless significant contributor to intraseasonal $\zeta$ variability in the Persian Gulf (Fig. 6). This is interesting, given that the barotropic ocean response to surface loading is generally expected to be isostatic on time scales longer than a few days (e.g., Wunsch and Stammer 1997; Ponte 2006). In our model physics, the dynamic response is permitted by friction through the Strait of Hormuz. Our finding that freshwater flux elicits a $\zeta$ response on the order of a few millimeters (Fig. 6) is consistent with the basic $\zeta$ magnitudes simulated for this region across subdaily to annual time scales by Ponte (2006) using a 1-yr simulation from a global barotropic ocean general circulation model forced with evaporation and precipitation (Hirose et al. 2001); however, that model was designed for global studies, and it used coarse resolution $\left(\sim 1^{\circ}\right)$ and a large friction coefficient $\left(2 \times 10^{-2} \mathrm{~m} \mathrm{~s}^{-1}\right)$, which may not accurately capture important physics in and around the Persian Gulf. Future studies using high-resolution ocean models would be informative for clarifying the nature of intraseasonal $\zeta$ variation in the Persian Gulf and the role of surface loading. Also relevant here is the fact that the nonisostatic response to barometric pressure is roughly in quadrature with the forcing (Table 4). This highlights the importance of considering phase information when testing for departures from a pure inverted-barometer response in sea level data (e.g., Mathers and Woodworth 2001, 2004).

Past studies argue that low-latitude wind forcing of the Indian Ocean related to large-scale climate modes excites wave responses that effect intraseasonal sea level variability along the Indian subcontinent and Maritime Continent, from Sumatra to western India (Cheng et al. 2013; Dhage and Strub 2016; Iskandar et al. 2005; Suresh et al. 2013). We provide evidence that these coastal-trapped waves continue propagating 


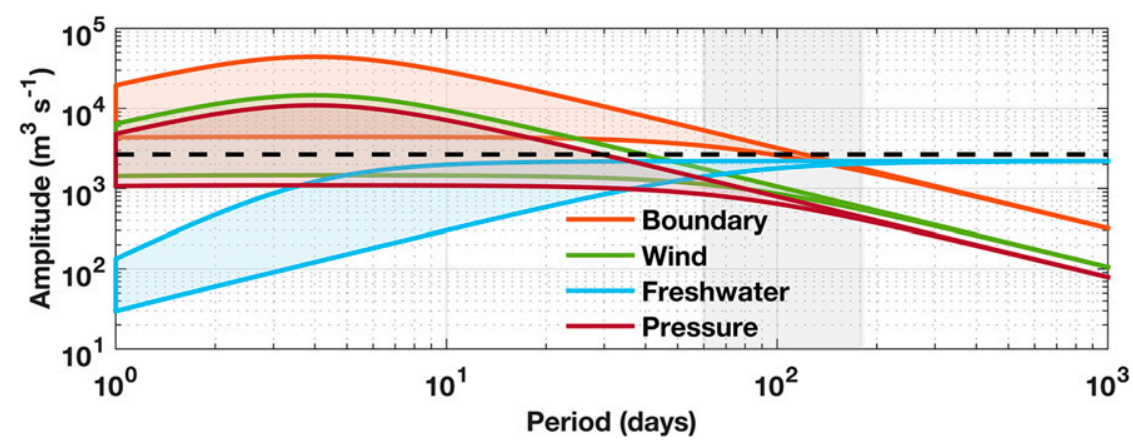

FIG. A1. Amplitude of $v W H$ response to boundary forcing $\zeta_{0}$ (orange), wind stress $\tau$ (green), freshwater flux $\bar{q}$ (blue), and barometric pressure $\bar{p}$ (red) as a function of period. Values are based on Eqs. (A4), (A6), (A8), and (A10) using parameter values from Table 3. Upper and lower lines are bounds determined by the range of friction coefficient $r$. See text for more details. Gray shading indicates intraseasonal periods of primary interest here. The dashed black line is the standard deviation of estimated transport described in the discussion section.

downstream and influence sea level in the Gulf of Oman and Persian Gulf (Figs. 8 and 9). We acknowledge that, while they suggest wave propagation, Figs. 8 and 9 could alternatively indicate the spatial scales of the atmospheric forcing. For example, large-scale wind forcing along the equator and off the southern tip of the Indian subcontinent could simultaneously excite equatorial waves and coastal waves propagating in the cyclonic sense along the west coast of the Indian subcontinent (e.g., Suresh et al. 2013; Dhage and Strub 2016). Future studies should identify the dominant centers of action of atmospheric forcing of intraseasonal $\zeta$ variability in the Persian Gulf, and whether coastal-trapped waves arriving in the Gulf of Oman have their origin in equatorial waves that impinged on the Maritime Continent. Our results also raise questions of whether such wave signals are felt even farther downstream along the coastal waveguide, for example, in the Red Sea. Previous investigations of sea level variability in the Red Sea on time scales from days to decades largely emphasize the role of more local forcing (Abdelrahman 1997; Churchill et al. 2018; Cromwell and Smeed 1998; Osman 1984; Patzert 1974; Sofianos and Johns 2001; Sultan and Elghribi 2003; Sultan et al. 1995b,c, 1996). However, recent work by Alawad et al. $(2017,2019)$ suggests that mean sea level variability in the Red Sea is partly related to large-scale modes of climate variability. These authors reason that this relationship is mediated by westward propagation of off-equatorial Rossby waves originating in the eastern tropical Indian Ocean. Based on our results, we hypothesize that coastal-wave propagation may also play a role in facilitating this relationship between sea level in the Red Sea and large-scale climate. We leave it to future studies to test this hypothesis.

Acknowledgments. The authors acknowledge support from NASA through the Sea Level Change Team (Grant 80NSSC20K1241) and GRACE Follow-On Science Team (Grant 80NSSC20K0728). The authors appreciate comments from two anonymous reviewers that improved the manuscript.

Data availability statement. Data are available through links provided in Table 1. MATLAB codes used for processing the data and producing the results are available from the corresponding author upon request.

\section{APPENDIX}

\section{Transport Variation through the Strait of Hormuz}

Insights onto the local and nonlocal forcing of transport variability through the Strait of Hormuz are given by our model. Substituting Eq. (3) for $\bar{\zeta}_{t}$ in Eq. (1), and assuming plane wave solutions, we obtain after rearranging and collecting terms,

$$
v W H=-i \omega S\left[\zeta_{0}+\frac{L}{\rho g H} \tau-\frac{i}{\omega} \bar{q}-\frac{\bar{p}}{\rho g}\right] /\left[1-\frac{\omega^{2}}{\sigma^{2}}-i \frac{\lambda \omega}{\sigma^{2}}\right]
$$

or, equivalently,

$$
\begin{aligned}
v W H= & \tilde{z}_{\zeta_{0}} \exp \left(i \tilde{\theta}_{\zeta_{0}}\right) \zeta_{0}+\tilde{z}_{\tau} \exp \left(i \tilde{\theta}_{\tau}\right) \tau+\tilde{z}_{\bar{q}} \exp \left(i \tilde{\theta}_{\bar{q}}\right) \bar{q} \\
& +\tilde{z}_{\bar{p}} \exp \left(i \tilde{\theta}_{\bar{p}}\right) \bar{p}
\end{aligned}
$$

where

$$
\begin{aligned}
& \tilde{\theta}_{\zeta_{0}} \doteq \arctan \left(\frac{\omega^{2}-\sigma^{2}}{\lambda \omega}\right), \\
& \tilde{z}_{\zeta_{0}} \doteq \omega S\left[\left(1-\frac{\omega^{2}}{\sigma^{2}}\right)^{2}+\left(\frac{\lambda \omega}{\sigma^{2}}\right)^{2}\right]^{-1 / 2}, \\
& \tilde{\theta}_{\tau} \doteq \arctan \left(\frac{\omega^{2}-\sigma^{2}}{\lambda \omega}\right), \\
& \tilde{z}_{\tau} \doteq \omega S\left[\left(1-\frac{\omega^{2}}{\sigma^{2}}\right)^{2}+\left(\frac{\lambda \omega}{\sigma^{2}}\right)^{2}\right]^{-1 / 2}\left(\frac{L}{\rho g H}\right), \\
& \tilde{\theta}_{\bar{q}} \doteq \arctan \left(\frac{\lambda \omega}{\sigma^{2}-\omega^{2}}\right),
\end{aligned}
$$




$$
\begin{aligned}
& \tilde{z}_{\bar{q}} \doteq S\left[\left(1-\frac{\omega^{2}}{\sigma^{2}}\right)^{2}+\left(\frac{\lambda \omega}{\sigma^{2}}\right)^{2}\right]^{-1 / 2}, \\
& \tilde{\theta}_{\bar{p}} \doteq \arctan \left(\frac{\omega^{2}-\sigma^{2}}{\lambda \omega}\right), \text { and } \\
& \tilde{z}_{\bar{p}} \doteq \frac{\omega S}{\rho g}\left[\left(1-\frac{\omega^{2}}{\sigma^{2}}\right)^{2}+\left(\frac{\lambda \omega}{\sigma^{2}}\right)^{2}\right]^{-1 / 2}
\end{aligned}
$$

To quantify the relative roles of the different surface and boundary forcing terms on transport as a function of time scale, we multiply the frequency-dependent scaling coefficients $\left[\tilde{z}_{j}\right.$ in Eqs. (A4), (A6), (A8), and (A10)] by the same forcing fluctuations that we used earlier in section $4 \mathrm{~b}$ and Fig. $7\left(\left|\zeta_{0}\right|=2 \mathrm{~cm}\right.$, $\left.|\tau|=0.005 \mathrm{~N} \mathrm{~m}^{-2},|\bar{q}|=1 \times 10^{-8} \mathrm{~m} \mathrm{~s}^{-1},|\bar{p}|=0.5 \mathrm{hPa}\right)$. Results are shown in Fig. A1. Resonant responses to $\zeta_{0}, \tau$, and $\bar{p}$ are seen near the Helmholtz period $2 \pi / \sigma \sim 4$ days, when maximum values $\left(\sigma^{2} S\left|\zeta_{0}\right| / \lambda, \sigma^{2} S|\tau| / \lambda \rho g H\right.$, and $\sigma^{2} S|\bar{p}| / \lambda \rho g$, respectively) are achieved. At periods shorter (longer) than $2 \pi / \sigma$, the transport response to $\zeta_{0}, \tau$, and $\bar{p}$ grows (decays) with period, such that $v W H \rightarrow 0$ as $\omega \rightarrow 0$. In contrast, the transport response to $\bar{q}$ increases universally with period, approaching the asymptotic limit $v W H \rightarrow S \bar{q}$ as $\omega \rightarrow 0$.

Given the amplitudes of the forcings, transport variations are predominantly driven by $\zeta_{0}$ and $\bar{q}$ on intraseasonal time scales. At longer time scales, forcing by $\bar{q}$ dominates, whereas $\zeta_{0}, \tau$, and $\bar{p}$ are more important drivers at shorter time scales. At all time scales, transport variations owing to local $\tau$ and $\bar{p}$ forcing are $\sim 1 / 3$ and $\sim 1 / 4$ as large, respectively, as transport variations due to nonlocal $\zeta_{0}$ forcing. This analytical exercise suggests that the intraseasonal transport variations through the Strait of Hormuz, estimated in the discussion, mainly reflect a combination of local $\bar{q}$ and nonlocal $\zeta_{0}$ forcing effects.

As discussed earlier, these results are a function of the forcing scales, details of friction, and the geometry of the region, and the various forcings could be more or less important if these parameters were different (e.g., for a different marginal sea).

\section{REFERENCES}

Abdelrahman, S. M., 1997: Seasonal fluctuations of mean sea level at Gizan, Red Sea. J. Coast. Res., 13, 1166-1172.

Ablain, M., and Coauthors, 2015: Improved sea level record over the satellite altimetry era (1993-2010) from the Climate Change Initiative project. Ocean Sci., 11, 67-82, https:// doi.org/10.5194/os-11-67-2015.

Adhikari, S., E. R. Ivins, T. Frederikse, F. W. Landerer, and L. Caron, 2019: Sea-level fingerprints emergent from GRACE mission data. Earth Syst. Sci. Data, 11, 629-646, https://doi.org/ 10.5194/essd-11-629-2019.

Adler, R. F., and Coauthors, 2003: The Version 2 Global Precipitation Climatology Project (GPCP) monthly precipitation analysis (1979-present). J. Hydrometeor., 4, 1147-1167, https://doi.org/10.1175/1525-7541(2003)004<1147:TVGPCP> 2.0.CO;2.

Ahmad, F., and S. A. R. Sultan, 1991: Annual mean surface heat fluxes in the Arabian Gulf and the net heat transport through the Strait of Hormuz. Atmos.-Ocean, 29, 54-61, https:// doi.org/10.1080/07055900.1991.9649392.
Alawad, K. I., A. M. Al-Subhi, M. A. Alsaafani, and T. M. Alraddadi, 2017: Signatures of tropical climate modes on the Red Sea and Gulf of Aden sea level. Indian J. Geo-Mar. Sci., 46, 2088-2096.

$\longrightarrow,-,-$, M. Ionita, and G. Lohmann, 2019: Large-scale mode impacts on the sea level over the Red Sea and Gulf of Aden. Remote Sens., 11, 2224, https://doi.org/10.3390/ rs11192224.

al-Chalabi, I., 2007: Oil. The geopolitics of oil and Iraq. N. Engl. J. Public Policy, 21, 136-139.

Al-Jeneid, S., M. Bahnassy, S. Nasr, and M. El Raey, 2008: Vulnerability assessment and adaptation to the impacts of sea level rise on the Kingdom of Bahrain. Mitigation Adapt. Strategies Global Change, 13, 87, https://doi.org/10.1007/s11027007-9083-8.

Alothman, A. O., M. S. Bos, R. M. S. Fernandes, and M. E. Ayhan, 2014: Sea level rise in the north-western part of the Arabian Gulf. J. Geodyn., 81, 105-110, https://doi.org/10.1016/ j.jog.2014.09.002.

Al-Subhi, A. M., 2010: Tide and sea level characteristics at Juaymah, west coast of the Arabian Gulf. J. King Abdulaziz Univ. Mar. Sci., 21, 133-149, https://doi.org/10.4197/Mar.21-1.8.

Amin, A., and K. Bankher, 1997: Causes of land subsidence in the Kingdom of Saudi Arabia. Nat. Hazards, 16, 57-63, https:// doi.org/10.1023/A:1007942021332.

Ayhan, M. E., 2020: Dynamic harmonic regression modeling for monthly mean sea levels at tide gauges within the Arabian Gulf. J. Geod., 94, 46, https://doi.org/10.1007/S00190-02001371-X.

Barnes, J., and A. Myers Jaffe, 2006: The Persian Gulf and the geopolitics of oil. Survival Global Polit. Strategy, 48, 143-162, https://doi.org/10.1080/00396330600594348.

Barzandeh, A., N. Eshghi, F. Hosseinibalam, and S. Hassanzadeh, 2018: Wind-driven coastal upwelling along the northern shoreline of the Persian Gulf. Boll. Geofis. Teor. Appl., 59, 301-302.

Bingham, R. J., and C. W. Hughes, 2008: The relationship between sea-level and bottom pressure variability in an eddy permitting ocean model. Geophys. Res. Lett., 35, L03602, https://doi.org/ 10.1029/2007GL032662.

Burgos, A. G., B. D. Hamlington, P. R. Thompson, and R. D. Ray, 2018: Future nuisance flooding in Norfolk, VA, from astronomical tides and annual to decadal internal climate variability. Geophys. Res. Lett., 45, 12 432-12 439, https://doi.org/ 10.1029/2018GL079572.

Cabanes, C., T. Huck, and A. Colin de Verdière, 2006: Contributions of wind forcing and surface heating to interannual sea level variations in the Atlantic Ocean. J. Phys. Oceanogr., 36, 1739-1750, https://doi.org/10.1175/JPO2935.1.

Carrère, L., and F. Lyard, 2003: Modeling the barotropic response of the global ocean to atmospheric wind and pressure forcing-Comparisons with observations. Geophys. Res. Lett., 30, 1275, https://doi.org/10.1029/2002GL016473.

_, Y. Faugère, and M. Ablain, 2016: Major improvement of altimetry sea level estimations using pressure-derived corrections based on ERA-Interim atmospheric reanalysis. Ocean Sci., 12, 825-842, https://doi.org/10.5194/os-12-825-2016.

Chao, S.-Y., T. W. Kao, and K. R. Al-Hajri, 1992: A numerical investigation of the circulation in the Arabian Gulf. J. Geophys. Res., 97, 11219-11 236, https://doi.org/10.1029/92JC00841.

Cheng, X., S.-P. Xie, J. P. Mc, Y. Creary, Y. Qi, and Y. Du, 2013: Intraseasonal variability of sea surface height in the Bay of Bengal. J. Geophys. Res. Oceans, 118, 816-830, https://doi.org/ 10.1002/jgrc.20075. 
Churchill, J. H., Y. Abualnaja, R. Limeburner, and M. Nellayaputhenpeedika, 2018: The dynamics of weatherband sea level variations in the Red Sea. Reg. Stud. Mar. Sci., 24, 336-342, https://doi.org/10.1016/j.rsma.2018.09.006.

Cromwell, D., and D. A. Smeed, 1998: Altimetric observations of sea level cycles near the Strait of Bab al Mandab. Int. J. Remote Sens., 19, 1561-1578, https://doi.org/10.1080/ 014311698215351.

Dangendorf, S., A. Arns, J. G. Pinto, P. Ludwig, and J. Jensen, 2016: The exceptional influence of storm 'Xaver' on design water levels in the German Bight. Environ. Res. Lett., 11, 054001, https://doi.org/10.1088/1748-9326/11/5/054001.

—, C. Hay, F. M. Calafat, M. Marcos, C. G. Piecuch, K. Berk, and J. Jensen, 2019: Persistent acceleration in global sea-level rise since the 1960s. Nat. Climate Change, 9, 705-710, https:// doi.org/10.1038/s41558-019-0531-8.

Dee, D. P., and Coauthors, 2011: The ERA-Interim reanalysis: Configuration and performance of the data assimilation system. Quart. J. Roy. Meteor. Soc., 137, 553-597, https://doi.org/ 10.1002/qj.828.

Dhage, L., and P. T. Strub, 2016: Intra-seasonal sea level variability along the west coast of India. J. Geophys. Res. Oceans, 121, 8172-8188, https://doi.org/10.1002/2016JC011904.

Efron, B., and T. Hastie, 2016: Computer Age Statistical Inference: Algorithms, Evidence, and Data Science. Cambridge University Press, 495 pp.

El-Gindy, A. A., and F. M. Eid, 1997: The seasonal variations of sea level due to density variations in the Arabian Gulf and Gulf of Oman. Pak. J. Marine Sci., 6, 1-12.

El-Gindy, A. A. H., 1991: Sea level variations and their relations to the meteorological factors in the Arab Gulf area with stress on monthly means. Int. Hydrogr. Rev., 68, 109-125.

Emery, K. O., 1956: Sediments and water in the Persian Gulf. Bull. Amer. Assoc. Pet. Geol., 40, 2354-2383.

Feng, W., M. Zhong, and H. Z. Xu, 2012: Sea level variations in the South China Sea inferred from satellite gravimetry, altimetry, and oceanographic data. Sci. China., 55D, 1696-1701, https:// doi.org/10.1007/s11430-012-4394-3.

_, J.-M. Lemoine, and M. Zhong, 2014: Mass-induced sea level variations in the Red Sea from GRACE, steric-corrected altimetry, in situ bottom pressure records, and hydrographic observations. J. Geodyn., 78, 1-7, https://doi.org/10.1016/ j.jog.2014.04.008.

Fenoglio-Marc, L., J. Kusche, and M. Becker, 2006: Mass variation in the Mediterranean Sea from GRACE and its validation by altimetry, steric and hydrologic fields. Geophys. Res. Lett., 33, L19606, https://doi.org/10.1029/2006GL026851.

—, R. Rietbroek, S. Grayek, M. Becker, J. Kusche, and E. Stanev, 2012: Water mass variation in the Mediterranean and Black Seas. J. Geodyn., 59-60, 168-182, https://doi.org/ 10.1016/j.jog.2012.04.001.

Frederikse, T., and Coauthors, 2020: The causes of sea-level rise since 1900. Nature, 584, 393-397, https://doi.org/10.1038/ s41586-020-2591-3.

Gill, A. E., 1982: Atmosphere-Ocean Dynamics. Academic Press, $680 \mathrm{pp}$.

— , and P. P. Niiler, 1973: The theory of the seasonal variability in the ocean. Deep-Sea Res., 20, 141-177, https://doi.org/10.1016/ 0011-7471(73)90049-1.

Good, S. A., M. J. Martin, and N. A. Rayner, 2013: EN4: Quality controlled ocean temperature and salinity profiles and monthly objective analyses with uncertainty estimates. J. Geophys. Res. Oceans, 118, 6704-6716, https://doi.org/10.1002/2013JC009067.
Gregory, J. M., and Coauthors, 2019: Concepts and terminology for sea level: Mean, variability and change, both local and global. Surv. Geophys., 40, 1251-1289, https://doi.org/10.1007/s10712019-09525-z.

Hassanzadeh, S., A. Kiasatpour, and F. Hosseinibalam, 2007: Sealevel response to atmospheric forcing along the north coast of Persian Gulf. Meteor. Atmos. Phys., 95, 223-237, https:// doi.org/10.1007/s00703-006-0213-8.

Hirose, N., I. Fukumori, V. Zlotnicki, and R. M. Ponte, 2001: Modeling the high-frequency barotropic response of the ocean to atmospheric disturbances: Sensitivity to forcing, topography, and friction. J. Geophys. Res., 106, 30 987-30 995, https:// doi.org/10.1029/2000JC000763.

Holgate, S. J., and Coauthors, 2013: New data systems and products and the Permanent Service for Mean Sea Level. J. Coast. Res., 29, 493-504, https://doi.org/10.2112/JCOASTRES-D12-00175.1.

Hosseinibalam, F., S. Hassanzadeh, and A. Kiasatpour, 2007: Interannual variability and seasonal contribution of thermal expansion to sea level in the Persian Gulf. Deep-Sea Res. I, 54, 1474-1485, https://doi.org/10.1016/j.dsr.2007.05.005.

Hughes, C. W., I. Fukumori, S. M. Griffies, J. M. Huthnance, S. Minobe, P. Spence, K. R. Thompson, and A. Wise, 2019: Sea level and the role of coastal trapped waves in mediating the influence of the open ocean on the coast. Surv. Geophys., 40, 1467-1492, https://doi.org/10.1007/s10712-019-09535-x.

Iskandar, I., W. Mardiansyah, Y. Masumoto, and T. Yamagata, 2005: Intraseasonal Kelvin waves along the southern coast of Sumatra and Java. J. Geophys. Res., 110, C04013, https:// doi.org/10.1029/2004JC002508.

Johns, W. E., G. A. Jacobs, J. C. Kindle, S. P. Murray, and M. Carron, 1999: Arabian Marginal Seas and Gulfs. University of Miami RSMAS Tech. Rep. 2000-01, 60 pp.

- F. Yao, D. B. Olson, S. A. Josey, J. P. Grist, and D. A. Smeed, 2003: Observations of seasonal exchange through the Straits of Hormuz and the inferred heat and freshwater budgets of the Persian Gulf. J. Geophys. Res., 108, 3391, https://doi.org/ 10.1029/2003JC001881.

Kämpf, J., and M. Sadrinasab, 2006: The circulation of the Persian Gulf: A numerical study. Ocean Sci., 2, 27-41, https://doi.org/ 10.5194/os-2-27-2006.

Kopp, R. E., R. M. Horton, C. M. Little, J. X. Mitrovica, M. Oppenheimer, D. J. Rasmussen, B. H. Strauss, and C. Tebaldi, 2014: Probabilistic 21st and 22nd century sea-level projections at a global network of tide-gauge sites. Earth's Future, 2, 383-406, https://doi.org/10.1002/2014EF000239.

—_, and Coauthors, 2017: Evolving understanding of Antarctic ice-sheet physics and ambiguity in probabilistic sea-level projections. Earth's Future, 5, 1217-1233, https://oi.org/ 10.1002/2017EF000663.

Lafta, A. A., S. A. Altaei, and N. H. Al-Hashimi, 2020: Impacts of potential sea-level rise on tidal dynamics in Khor Abdullah and Khor Al-Zubair, northwest of Arabian Gulf. Earth Syst. Environ., 4, 93-105, https://doi.org/10.1007/s41748020-00147-9.

Landerer, F. W., and D. L. Volkov, 2013: The anatomy of recent large sea level fluctuations in the Mediterranean Sea. Geophys. Res. Lett., 40, 553-557, https://doi.org/10.1002/ grl.50140.

— record: GRACE Follow-On instrument and science data performance. Geophys. Res. Lett., 47, e2020GL088306, https:// doi.org/10.1029/2020GL088306. 
Large, W. G., and S. G. Yeager, 2004: Diurnal to decadal global forcing for ocean and sea-ice models: The data sets and flux climatologies. NCAR Tech. Note NCAR/TN-460+STR, 105 pp., https://doi.org/10.5065/D6KK98Q6.

Larson, A., 2007: Oil. The geopolitics of oil and natural gas. N. Engl. J. Public Policy, 21, 215-219.

Legeais, J.-F., and Coauthors, 2018: An improved and homogeneous altimeter sea level record from the ESA Climate Change Initiative. Earth Syst. Sci. Data, 10, 281-301, https:// doi.org/10.5194/essd-10-281-2018.

Long, X., M. J. Widlansky, F. Schloesser, P. R. Thompson, H. Annamalai, M. A. Merrifield, and H. Yoon, 2020: Higher sea levels at Hawaii caused by strong El Niño and weak trade winds. J. Climate, 33, 3037-3059, https://doi.org/10.1175/JCLID-19-0221.1.

Loomis, B. D., and S. B. Luthcke, 2017: Mass evolution of Mediterranean, Black, Red, and Caspian Seas from GRACE and altimetry: Accuracy assessment and solution calibration. J. Geod., 91, 195-206, https://doi.org/10.1007/s00190-016-0952-3.

Mathers, E. L., and P. L. Woodworth, 2001: Departures from the local inverse barometer model observed in altimeter and tide gauge data and in a global barotropic numerical model. J. Geophys. Res., 106, 6957-6972, https://doi.org/10.1029/ 2000JC000241.

$\longrightarrow$, and - 2004: A study of departures from the inversebarometer response of sea level to air-pressure forcing at a period of 5 days. Quart. J. Roy. Meteor. Soc., 130, 725-738, https://doi.org/10.1256/qj.03.46.

Meyssignac, B., C. G. Piecuch, C. J. Merchant, M.-F. Racault, H. Palanisamy, C. MacIntosh, S. Sathyendranath, and R. Brewin, 2017: Causes of the regional variability in observed sea level, sea surface temperature and ocean colour over the period 1993-2011. Surv. Geophys., 38, 187-215, https://doi.org/ 10.1007/s10712-016-9383-1.

Nerem, R. S., B. D. Beckley, J. T. Fasullo, B. D. Hamlington, D. Masters, and G. T. Mitchum, 2018: Climate-change-driven accelerated sea-level rise detected in the altimeter era. Proc. Natl. Acad. Sci. USA, 115, 2022-2025, https://doi.org/10.1073/ pnas. 1717312115 .

Oliver, E. C. J., and K. R. Thompson, 2010: Madden-Julian Oscillation and sea level: Local and remote forcing. J. Geophys. Res., 115, C01003, https://doi.org/10.1029/2009JC005337.

Osman, M. M., 1984: Variation of sea level at Port-Sudan. Int. Hydrogr. Rev., 61, 137-144.

Patzert, W. C., 1974: Wind-induced reversal in Red Sea circulation. Deep-Sea Res. Oceanogr. Abstr., 21, 109-121, https://doi.org/ 10.1016/0011-7471(74)90068-0.

Piecuch, C. G., and R. M. Ponte, 2015: A wind-driven nonseasonal barotropic fluctuation of the Canadian inland seas. Ocean Sci., 11, 175-185, https://doi.org/10.5194/os-11-175-2015.

— K. Kittermann, A. C. Kemp, R. M. Ponte, C. M. Little, S. E. Engelhart, and S. J. Lentz, 2018a: River-discharge effects on United States Atlantic and Gulf coast sea-level changes. Proc. Natl. Acad. Sci. USA, 115, 7729-7734, https://doi.org/10.1073/ pnas. 1805428115.

— , F. W. Landerer, and R. M. Ponte, 2018b: Tide gauge records reveal improved processing of Gravity Recovery and Climate Experiment time-variable mass solutions over the coastal ocean. Geophys. J. Int., 214, 1401-1412, https://doi.org/10.1093/gji/ggy207.

_ , F. M. Calafat, S. Dangendorf, and G. Jordà, 2019: The ability of barotropic models to simulate historical mean sea level changes from coastal tide gauge data. Surv. Geophys., 40, 1399-1435, https://doi.org/10.1007/s10712-019-09537-9.
Ponte, R. M., 1994: Understanding the relation between windand pressure-driven sea level variability. J. Geophys. Res., 99, 8033-8039, https://doi.org/10.1029/94JC00217.

- 2006: Oceanic response to surface loading effects neglected in volume-conserving models. J. Phys. Oceanogr., 36, 426-434, https://doi.org/10.1175/JPO2843.1.

Privett, D. W., 1959: Monthly charts of evaporation from the N. Indian Ocean (including the Red Sea and the Persian Gulf). Quart. J. Roy. Meteor. Soc., 85, 424-428, https://doi.org/10.1002/ qj.49708536614.

PSMSL, 2020: Tide gauge data. Permanent Service for Mean Sea Level, accessed 1 July 2019, http://www.psmsl.org/data/ obtaining/.

Quartly, G. D., and Coauthors, 2017: A new phase in the production of quality-controlled sea level data. Earth Syst. Sci. Data, 9, 557-572, https://doi.org/10.5194/essd-9-557-2017.

Ray, R. D., and G. Foster, 2016: Future nuisance flooding at Boston caused by astronomical tides alone. Earth's Future, 4, 578-587, https://doi.org/10.1002/2016EF000423.

Reynolds, R. M., 1993: Physical oceanography of the Gulf, Strait of Hormuz, and the Gulf of Oman-Results from the Mt Mitchell expedition. Mar. Pollut. Bull., 27, 35-59, https:// doi.org/10.1016/0025-326X(93)90007-7.

Rohith, B., A. Paul, F. Durand, L. Testut, S. Prerna, M. Afroosa, S. S. V. S. Ramkrishna, and S. S. C. Shenoi, 2019: Basin-wide sea level coherency in the tropical Indian Ocean driven by Madden-Julian Oscillation. Nat. Commun., 10, 1257, https:// doi.org/10.1038/s41467-019-09243-5.

Sharaf El Din, S. H., 1990: Sea level variation along the western coast of the Arabian Gulf. Int. Hydrogr. Rev., 67, 103-109.

Siddig, N. A., A. M. Al-Subhi, and M. A. Alsaafani, 2019: Tide and mean sea level trend in the west coast of the Arabian Gulf from tide gauges and multi-missions satellite altimeter. Oceanologia, 61, 401-411, https://doi.org/10.1016/j.oceano.2019.05.003.

Sofianos, S. S., and W. E. Johns, 2001: Wind induced sea level variability in the Red Sea. Geophys. Res. Lett., 28, 3175-3178, https://doi.org/10.1029/2000GL012442.

Sultan, S. A. R., and N. M. Elghribi, 2003: Sea level changes in the central part of the Red Sea. Indian J. Geo-Mar. Sci., 32, 114122.

, F. Ahmad, N. M. Elghribi, and A. M. Al-Subhi, 1995a: An analysis of Arabian Gulf monthly mean sea level. Cont. Shelf Res., 15, 1471-1482, https://doi.org/10.1016/0278-4343(94) 00081-W.

,-- , and $—$ 1995b: Sea level variability in the central Red Sea. Oceanol. Acta, 18, 607-615.

,$- \ldots$, and A. El-Hassan, 1995c: Seasonal variations of the sea level in the central part of the Red Sea. Estuarine Coastal Shelf Sci., 40, 1-8, https://doi.org/10.1016/0272-7714(95)90008-X.

$\longrightarrow,-$, and D. Nassar, 1996: Relative contribution of external sources of mean sea-level variations at Port Sudan, Red Sea. Estuarine Coastal Shelf Sci., 42, 19-30, https://doi.org/10.1006/ ecss.1996.0002.

_, M. O. Moamar, N. M. El-Ghribi, and R. Williams, 2000: Sea level changes along the Saudi coast of the Arabian Gulf. Indian J. Geo-Mar. Sci., 29, 191-200.

Suresh, I., J. Vialard, M. Lengaigne, W. Han, J. McCreary, F. Durand, and P. M. Muraleedharan, 2013: Origins of winddriven intraseasonal sea level variations in the north Indian Ocean coastal waveguide. Geophys. Res. Lett., 40, 5740-5744, https://doi.org/10.1002/2013GL058312.

,,-- T. Izumo, M. Lengaigne, W. Han, J. McCreary, and P. M. Muraleedharan, 2016: Dominant role of winds near Sri 
Lanka in driving seasonal sea level variations along the west coast of India. Geophys. Res. Lett., 43, 7028-7035, https:// doi.org/10.1002/2016GL069976.

Sweet, W. V., M. Menendez, A. Genz, J. Obeysekera, J. Park, and J. J. Marra, 2017: In tide's way: Southeast Florida's September 2015 sunny-day flood. Bull. Amer. Meteor. Soc., 97, S25-S30, https://doi.org/10.1175/BAMS-D-16-0117.1.

Swift, S. A., and A. S. Bower, 2003: Formation and circulation of dense water in the Persian/Arabian Gulf. J. Geophys. Res., 108, 3004, https://doi.org/10.1029/2002JC001360.

Thoppil, P. G., and P. J. Hogan, 2010: A modeling study of circulation and eddies in the Persian Gulf. J. Phys. Oceanogr., 40, 2122-2134, https://doi.org/10.1175/2010JPO4227.1.

Tregoning, P., K. Lambeck, and G. Ramillien, 2008: GRACE estimates of sea surface height anomalies in the Gulf of Carpentaria, Australia. Earth Planet. Sci. Lett., 271, 241-244, https://doi.org/10.1016/j.epsl.2008.04.018.

Tsujino, H., and Coauthors, 2018: JRA-55 based surface dataset for driving ocean-sea-ice models (JRA55-do). Ocean Modell., 130, 79-139, https://doi.org/10.1016/j.ocemod.2018.07.002.

Vinogradova, N. T., R. M. Ponte, and D. Stammer, 2007: Relation between sea level and bottom pressure and the vertical dependence of oceanic variability. Geophys. Res. Lett., 34, L03608, https://doi.org/10.1029/2006GL028588.

Vivier, F., K. A. Kelly, and L. Thompson, 1999: Contributions of wind forcing, waves, and surface heating to sea surface height observations in the Pacific Ocean. J. Geophys. Res., 104, 20 767-20 788, https://doi.org/10.1029/1999JC900096.

Volkov, D. L., W. E. Johns, and T. B. Belonenko, 2016: Dynamic response of the Black Sea elevation to intraseasonal fluctuations of the Mediterranean sea level. Geophys. Res. Lett., 43, 283-290, https://doi.org/10.1002/2015GL066876.

von Storch, H., and F. W. Zwiers, 1999: Statistical Analysis in Climate Research. Cambridge University Press, 496 pp.

Wahr, J. W., D. A. Smeed, E. Leuliette, and S. Swenson, 2014: Seasonal variability of the Red Sea, from satellite gravimetry, radar altimetry, and in situ observations. J. Geophys. Res. Oceans, 119, 5091-5104, https://doi.org/10.1002/2014JC010161.

Waliser, D. E., R. Murtugudde, and L. E. Lucas, 2003a: IndoPacific Ocean response to atmospheric intraseasonal variability: 1. Austral summer and the Madden-Julian Oscillation. J. Geophys. Res., 108, 3160, https://doi.org/10.1029/2002JC001620.

,-- , and - 2003b: Indo-Pacific Ocean response to atmospheric intraseasonal variability: 2 . Boreal summer and the Intraseasonal Oscillation. J. Geophys. Res., 109, 3160, https:// doi.org/10.1029/2002JC001620.

Wang, J., J. Wang, and X. Cheng, 2015: Mass-induced sea level variations in the Gulf of Carpentaria. J. Oceanogr., 71, 449461, https://doi.org/10.1007/s10872-015-0304-6.

Watkins, M. M., D. N. Wiese, D.-H. Yuan, C. Boening, and F. W. Landerer, 2015: Improved methods for observing Earth's time variable mass distribution with GRACE using spherical cap mascons. J. Geophys. Res. Solid Earth, 120, 2648-2671, https:// doi.org/10.1002/2014JB011547.

Wiese, D. N., F. W. Landerer, and M. M. Watkins, 2016: Quantifying and reducing leakage errors in the JPL RL05M GRACE mascon solution. Water Resour. Res., 52, 7490-7502, https://doi.org/10.1002/2016WR019344.

Wouters, B., and D. Chambers, 2010: Analysis of seasonal ocean bottom pressure variability in the Gulf of Thailand from GRACE. Global Planet. Change, 74, 76-81, https://doi.org/ 10.1016/j.gloplacha.2010.08.002.

Wunsch, C., and D. Stammer, 1997: Atmospheric loading and the oceanic "inverted barometer" effect. Rev. Geophys., 35, 79107, https://doi.org/10.1029/96RG03037.

Yao, F., and W. E. Johns, 2010: A HYCOM modeling study of the Persian Gulf: 1. Model configurations and surface circulation. J. Geophys. Res., 115, C11017, https://doi.org/10.1029/ 2009JC005781.

Yu, L., and R. A. Weller, 2007: Objectively analyzed air-sea heat fluxes for the global ice-free oceans (1981-2005). Bull. Amer. Meteor. Soc., 88, 527-540, https://doi.org/10.1175/BAMS-88-4-527. 